Review

\title{
The Architecture of Mass Customization-Social Internet of Things System: Current Research Profile
}

\author{
Zixin Dou ${ }^{1}$, Yanming Sun ${ }^{1,2, *}$, Zhidong $W u^{3}$, Tao Wang ${ }^{4}{ }^{\oplus}$, Shiqi Fan ${ }^{5}{ }^{(}$and Yuxuan Zhang ${ }^{6}$ \\ 1 School of Management, Guangzhou University, Guangzhou 510000, China; 1111965001@e.gzhu.edu.cn \\ 2 Research Center for High Quality Development of Modern Industry, Guangzhou University, \\ Guangzhou 510000, China \\ 3 Algorithm Research Center, Joyy Inc., Guangzhou 510000, China; wuzhidong@joyy.sg \\ 4 Department of Building Surveying, Faculty of Built Environment, University of Malaya, \\ Kuala Lumpur 50603, Malaysia; 17221416@siswa.um.edu.my \\ 5 Department of Engineering, The University of Hong Kong, Hong Kong 999077, China; \\ fsq247@connect.hku.hk \\ 6 Warwick Business School, The University of Warwick, Coventry CV4 7AL, UK; \\ yuxuan.zhang.4@warwick.ac.uk \\ * Correspondence: sunyanming@gzhu.edu.cn
}

check for updates

Citation: Dou, Z.; Sun, Y.; Wu, Z.; Wang, T.; Fan, S.; Zhang, Y. The Architecture of Mass

Customization-Social Internet of Things System: Current Research Profile. ISPRS Int. J. Geo-Inf. 2021, 10, 653. https://doi.org/10.3390/ ijgi10100653

\section{Academic Editors:}

Fernando Terroso-Sáenz, Andrés Muñoz and Wolfgang Kainz

Received: 16 July 2021

Accepted: 27 September 2021

Published: 28 September 2021

Publisher's Note: MDPI stays neutral with regard to jurisdictional claims in published maps and institutional affiliations.

Copyright: (c) 2021 by the authors. Licensee MDPI, Basel, Switzerland. This article is an open access article distributed under the terms and conditions of the Creative Commons Attribution (CC BY) license (https:/ / creativecommons.org/licenses/by/ $4.0 /)$

\begin{abstract}
In the era of big data, mass customization (MC) systems are faced with the complexities associated with information explosion and management control. Thus, it has become necessary to integrate the mass customization system and Social Internet of Things, in order to effectively connecting customers with enterprises. We should not only allow customers to participate in MC production throughout the whole process, but also allow enterprises to control all links throughout the whole information system. To gain a better understanding, this paper first describes the architecture of the proposed system from organizational and technological perspectives. Then, based on the nature of the Social Internet of Things, the main technological application of the mass customization-Social Internet of Things (MC-SIOT) system is introduced in detail. On this basis, the key problems faced by the mass customization-Social Internet of Things system are listed. Our findings are as follows: (1) MC-SIOT can realize convenient information queries and clearly understand the user's intentions; (2) the system can predict the changing relationships among different technical fields and help enterprise R\&D personnel to find technical knowledge; and (3) it can interconnect deep learning technology and digital twin technology to better maintain the operational state of the system. However, there exist some challenges relating to data management, knowledge discovery, and human-computer interaction, such as data quality management, few data samples, a lack of dynamic learning, labor consumption, and task scheduling. Therefore, we put forward possible improvements to be assessed, as well as privacy issues and emotional interactions to be further discussed, in future research. Finally, we illustrate the behavior and evolutionary mechanism of this system, both qualitatively and quantitatively. This provides some idea of how to address the current issues pertaining to mass customization systems.
\end{abstract}

Keywords: big data; mass customization; technology application; intelligent system

\section{Introduction}

With the development of next-generation technology, such as cyber-physical systems [1], the Internet of Things (IOT) [2], data mining [3], and Industry 4.0 [4], producing customized products in an industrial environment has arisen [5]. Mass customization (MC) has reformed the service-oriented behavior of manufacturing enterprises, providing some standard operating procedures for both the buyer and the seller [6]. It provides diversified and inexpensive production modes [7], including modular products, service design, and flexible manufacturing processes [8,9]. Therefore, it can provide customers with a convenient shopping experience, as well as novel products and services $[10,11]$. This can urge a 
company to meet its customer's needs [12] by improving their responsiveness in terms of product design and manufacturing. Therefore, it can help manufacturing enterprises to gain competitive advantages in the market [13].

In recent years, a large number of scholars have studied $\mathrm{MC}$, which has become an important driving force for competitive advantages in various industries [14], including electronic products [15], large engineering products [16], personalized nutrition [17], home building [18], and so on. However, in a traditional MC system, the collected data are not available at a specific point in time, and cannot be read when humans or machines can make the most use of them [19]. In addition, standard operating procedures cannot be as smooth as usual with MC, and even face problems of internal and external interference in a highly dynamic environment [20-22]. This inevitably causes the manufacturers and customers involved in the MC system to feel uneasy. For these reasons, many scholars have focused on this topic. For example, Larrea et al. [23] have analyzed the factors influencing customer-driven production. Nemechansky et al. [24] have developed a customer-driven model to view the enterprise cost structure. However, the above literature lacked an in-depth exploration of the MC architecture. In the era of big data in particular, any MC system is faced with complexities related to information explosion and management control. Therefore, the existing system functions need to effectively connect people and things.

In the era of big data, IOT is being combined with social networks. Social networks not only include the relationships between things, as well as those between things and people, but also the relationships between people. They can better describe the world of the "Internet of Everything". Thus, the concept of the Social Internet of Things (SIOT) [25] has been proposed. The SIOT goes beyond the traditional IOT and enhances environmental awareness. In other words, context-aware services can be generated, according to the user's situational needs and environment [26]. The SIOT concept has recently attracted considerable attention. For example, Nitti et al. [27] focused on how to deal with the information provided by SIOT members, such that they could independently establish a relationship network, while Chen et al. [28] regarded SIOT as a knowledge graph to understand user preferences through potential variables. Son et al. [29] have proposed a trust-aware recommendation system suitable for SIOT. It can more accurately predict user preferences. However, the abovementioned literature lacked an exploration of the combination of SIOT and an enterprise information system, such as specific technological applications and key problems in its production process. Particularly: (1) In terms of human-to-human interactions $(\mathrm{HH})$, due to the various product information released by enterprise personnel, it is difficult for customers to find the products they need [30]. At the same time, employees cannot quickly process online reviews by customers; (2) In terms of human-to-thing interactions (HT), the R\&D department needs to design products according to product innovation trends. If enterprises do not have an effective way to obtain information, they will lack the ability to perceive internal and external product innovation in time. This leads to backward product development and design and the loss of potential customers [31]; and (3) In terms of thing-to-thing interactions (TT), with the expansion of information system network space and physical space, equipment failure will significantly affect the production progress of products. Therefore, equipment reliability prediction is particularly important [32]. In short, it is necessary to effectively integrate SIOT and MC systems to meet the above requirements.

To address these knowledge gaps, we constructed the MC-SIOT system architecture from the perspectives of management and technology. According to the characteristics of the MC-SIOT system, its main intended uses are introduced in detail, including application scenarios and its application value. Then, the key problems of the system are listed, in terms of data management, knowledge discovery, and human-computer interaction. Finally, to deeply understand the system, we illustrate its behavior and evolutionary mechanism, both qualitatively and quantitatively. This will serve to pave the way for coping with some challenges of the MC-SIOT system from new perspectives. 
The rest of the paper is organized as follows: Section 2 provides an analysis of the related literature. The following section introduces the architecture of the MC-SIOT system. Its main technological applications are described in Section 4. Section 5 discusses the key problems. Section 6 analyzes the MC-SIOT system, both qualitatively and quantitatively. Section 7 discusses the research limitations and future directions. Finally, our conclusions are presented.

\section{Literature Analysis}

To select relevant publications within the current research topic, we utilized the reliable and comprehensive database Web of Science (www.webofscience.com, accessed on 24 September 2021). This database provided high coverage of articles related to our research. Therefore, the chance of missing any relevant paper was reduced. The combination of MC and SIOT is a new topic. Therefore, we used the following keywords as the primary factors to control the search results: "IOT", "deep learning", "semantic analysis", and "knowledge graph". To ensure that all relevant keywords were included, more than 20 of the most relevant papers in the field were reviewed. This process is called a pilot review.

Due to the continuous progress of technology, the IOT field is booming [33]. Figure 1 shows that the use of the IOT involves different technologies, such as deep learning, knowledge graphs, and semantics. These algorithms interact within the IOT. It is worth noting that these algorithms often have different purposes. Some relevant studies are briefly detailed in the following:

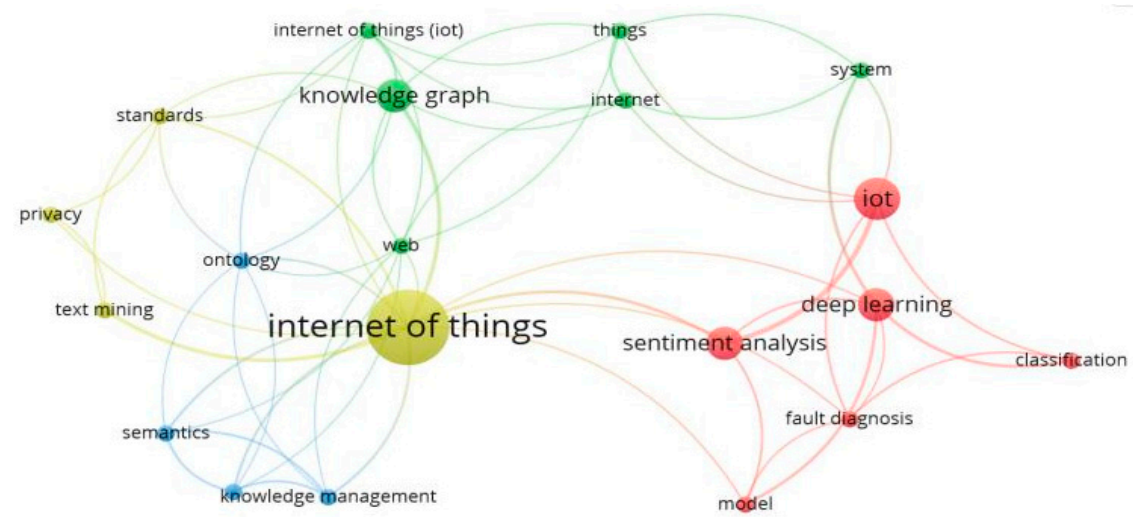

Figure 1. Co-occurrence analytical map of keywords.

Alzahrani [34] have proposed an IOT mining machine which uses a pre-programmed raspberry $\mathrm{Pi}$ for emotion analysis and opinion generation on intelligent images. A naive Bayesian classifier was used for opinion mining in IOT devices. Their experimental results showed its feasibility and effectiveness. Based on the IOT architecture, Htet et al. [35] have proposed a medical care system using the MaxEnt classifier. Specifically, the corresponding feature set is added to the feature vector and stored in the cloud database server. It can efficiently process massive user data. Psomakelis et al. [36] have proposed a platform based on a service-oriented architecture, which can retrieve and analyze large data sets from social network sites and IOT devices. Liu et al. [37] proposed a crowdsourcing-based topic model framework, which extends the classical knowledge representation framework. It not only improves the quality-of-service information extraction, but also improves the effectiveness of service matching in IOT services. Bermudez-Edo et al. [38] proposed a lightweight semantic IOT model. This model is an example of semantic sensor network ontology, which can be used to describe the key concepts of IOT. It allows interoperability in heterogeneous IOT platforms through lightweight semantics. Liu et al. [39] proposed a device-oriented automatic semantic annotation method for IOT device information. This method can automatically extract key information, partition information, expand equipment ontology, and match concepts in equipment ontology. It can solve the problem of information interaction between classified, heterogeneous, and distributed devices. Xie et al. [40] believed that the 
communication gap and heterogeneous access hinder the effective application of existing IOT systems. They proposed a multi-layer IOT framework to bridge the gap between IOT devices with different communication protocols. Gómez-Berbís et al. [41] have proposed a semantic digital twin based on IoT data management and knowledge graphs, which is compatible with various databases and different data structures. Khokhlov et al. [42] have proposed a general framework to integrate data quality assessment into a wide range of IOT applications. In the proposed framework, the knowledge graph plays a vital role in connecting all framework components. Li et al. [43] have proposed a semantic collaboration method based on the uniform knowledge graph. The semantic relationship between two different data sets is obtained by constructing semantic links, and is combined with the advantages of knowledge graphs in knowledge representation and processing, which provides a useful data basis for semantic collaboration. This method can better analyze and understand the semantics of user requirements. Liu et al. [44] have proposed a Chinese medical knowledge graph method based on IOT and Web of Things concepts. This method uses a deep neural network combined with self-attention to generate a knowledge graph. Karim et al. [45] have proposed DESERT, a query engine that can decompose and semantically enrich streaming data on demand. It can effectively integrate IOT data from different streaming data sources. Yao et al. [46] have collected data using IOT technology and used an SVM BiLSTM algorithm for fault detection. The operational data collected by the system from the edge of the IOT gateway were compared with the human emotional response data. The results showed that the algorithm can detect faults in an IOT system effectively and accurately. Hou et al. [47] have applied a deep learning method to the real-time monitoring of power IOT equipment, which helps staff to locate faults quickly and accurately. Benkedjouh et al. [48] have used deep learning to improve the accuracy of rotating machinery fault diagnosis in an Internet of Things framework. They considered how to select features from the STFT matrix by deep learning, in order to maximize the accuracy of fault detection. Zhang et al. [49] have proposed a new transformer fault diagnosis method based on an IOT monitoring system and ensemble machine learning. The system extracts features using a deep belief network and uses restricted Boltzmann machines to identify faults, according to their features. An effective combination strategy can significantly improve the diagnostic performance. Chen et al. [50] have created a deep learning model within an IOT framework to diagnose the faults in a wind power generation system. It can realize undisturbed switching from normal system control to fault system control. In the case of sensor failure, this method can carry out fault-tolerant control for the system, allowing it to have good dynamic performance.

The applications of these technologies mainly involve data management, knowledge discovery, and human-computer interaction (see Table 1). In terms of semantic analysis, [34,39] used semantic technology to solve data management problems in the IOT framework, such as data heterogeneity and fast retrieval. Regarding knowledge framework and human-computer interaction, Liu et al. [37] extended the knowledge representation framework by considering subject modeling and human cognition. Liu et al. [39] proposed automatic semantic annotation of IOT devices, which solves the key problem of interaction. Htet et al. [35] have proposed an IOT-big data framework which can mine massive user information to understand the situations of users. It also belongs to the field of knowledge discovery.

Table 1. Applications of technology in different fields.

\begin{tabular}{cccc}
\hline & Data Management & $\begin{array}{c}\text { Knowledge } \\
\text { Discovery }\end{array}$ & $\begin{array}{c}\text { Human Computer } \\
\text { Interaction }\end{array}$ \\
\hline Semantics analysis & $\sqrt{ }$ & $\sqrt{ }$ & $\sqrt{ }$ \\
\hline Knowledge graph & $\sqrt{ }$ & $\sqrt{ }$ & $\sqrt{ }$ \\
\hline Deep learning & $\sqrt{ }$ & $\sqrt{ }$ &
\end{tabular}

Note: " $\sqrt{ }$ " stands for whether the technology is applied to this scenario. 
In terms of the knowledge graphs, the studies $[40,45]$ have shown that, by generating various types of knowledge graphs, people can better analyze data and understand user needs. The above literature also involves two other aspects; for example, Gómez-Berbís et al. [41] have proposed SEDIT, based on knowledge atlas technology. It is compatible with databases and different data structures, and can effectively manage IOT data. Xie et al. [40] used an IOT knowledge graph to manage all IOT devices in a system, which solved the communication gap and heterogeneous access problems in the system, as well as facilitating interactions between the operator and the system.

In terms of deep learning, the studies $[46,50]$ have shown that, in the IOT framework, the faults of IOT devices can be found quickly through use of a deep learning algorithm. This can help staff to quickly understand the status of equipment. It also involves data management and knowledge discovery. For example, Zhang et al. [49] have proposed EML, which can effectively extract feature information from data. This makes up for the deficiency of traditional methods in extracting feature information. It belongs to the problem of knowledge discovery. Yao et al. [46] have compared the operations data in an IOT system with human emotional response data. By managing the above data, they discovered the abnormal values in IOT system data and detected faults. This was also a data management issue.

In summary, due to the continuous progress of technology, there has been an upsurge of Internet of Things applications, which can combine various advanced technologies [33]. The IOT is a network of interconnected computing devices that can transmit valuable data to each other through the Internet. It plays an important role in data management, knowledge discovery, and user interaction. However, in the context of massive user information, the traditional IOT cannot effectively manage customer data in the scenario of MC. Therefore, SIOT has become an emerging trend. Through the integration of social networks and IOT, the SIOT uses the social relationships between people and between people and things. This can effectively connect the social network's customer base with the enterprise. It not only allows customers to participate in the MC production process, but also allows enterprises to control all links through the whole information system. Key aspects of SOIT are detailed in the following.

Technical models can be developed for customer service; for example, Li et al. [51] have proposed a subscription model based on the mobile community by using the longterm neighbor relationship between nodes to improve the service quality of a delay-tolerant network. Based on the hyper-graph model, Jung et al. [52] used hyper-edges to describe a variety of potential relationships between nodes, thus enriching the relationship model of SIOT. Based on the interests of users and the mobility of nodes, Qureshi et al. [53] have proposed an adaptive content sharing protocol, thus improving the content dissemination effect of peer-to-peer mobile social networks.

Technical models can also developed for enterprise management; for example, considering various heterogeneous sensor networks, Qiu et al. [54] established the small-world network topology model of SIOT, in order to ensure the normal operations of the data nodes. Kang et al. [55] have proposed the SDIF framework, which makes collaboration between devices easier by providing social relationships between devices. Lee et al. [56] have combined the analysis of social networks and the social attributes of devices to realize information sharing between devices. Turcu et al. [57] have proposed a cognitive robot based on RFID technology, in order to realize specific behavior when interacting with the environment.

Therefore, by introducing SIOT into the MC system, people and things can be effectively connected. This can solve the problems relating to the complexity of information expansion and management control.

\section{The MC-SIOT System Architecture}

The process of the MC-SIOT system is different from that of traditional MC systems, as shown in Figure 2. All departments of the MC-SIOT system are interconnected and can 
exchange data at any time, through use of a huge computer system. According to customer orders and market demand, the system carries out product design, ensures the production schedule, and produces products for customers. It is worth noting that, if an enterprise lacks cooperation initiatives and comprehensive knowledge at the department level, it will not be able to achieve sustainable development [58]. To meet this challenge, enterprises should apply the new system in line with the production process. In this paper, we describe the MC-SIOT system architecture. The next two subsections analyze the MC-SIOT system from the perspectives of organization and technology, respectively.

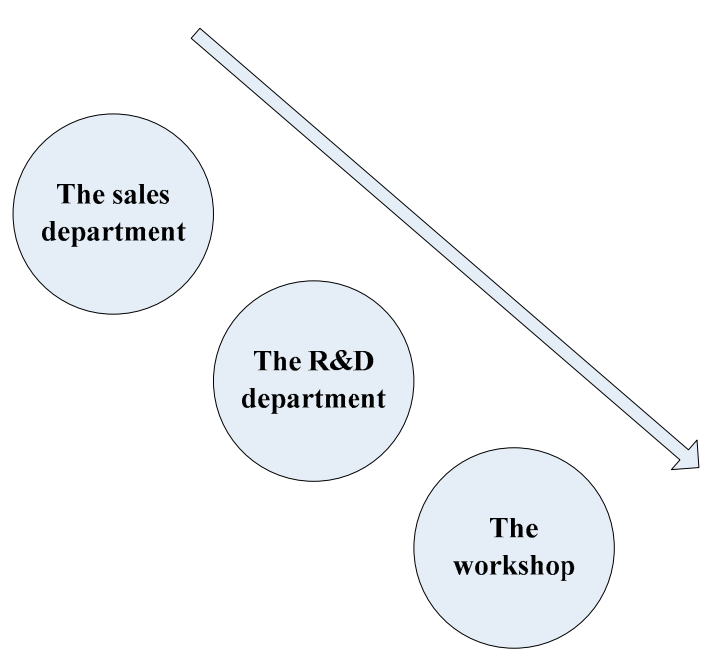

(a)

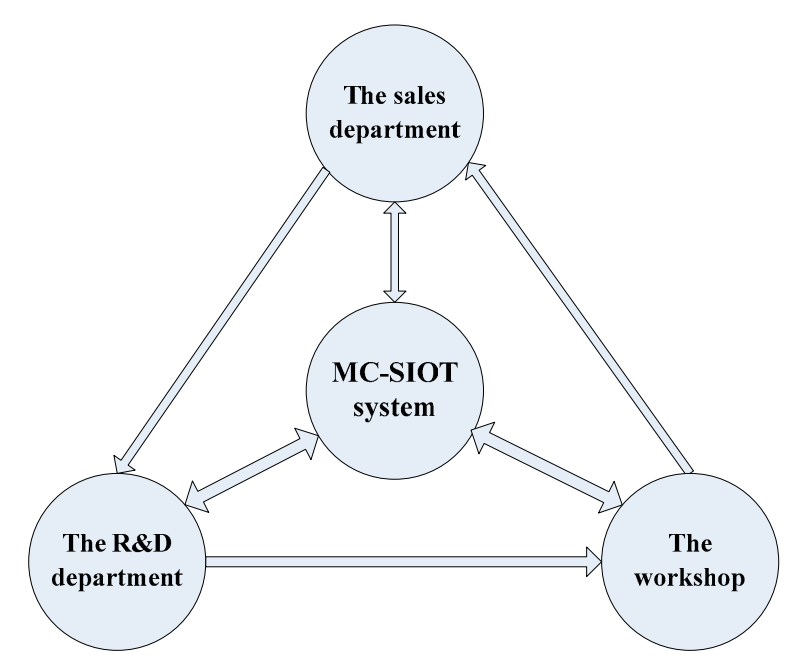

(b)

Figure 2. (a) Traditional MC system. (b) MC-SIOT system.

\subsection{The Organizational Architecture of the MC-SIOT System}

The MC-SIOT system is composed of a series of inter-related value creation activities, such as R\&D design, production, processing, and sales. Data exchange and knowledge integration among all links are the important premises of MC-SIOT system management. On the basis of Song et al. [19] and Liang et al. [59], the organizational architecture of the MC-SIOT system comprises two parts (Figure 3): A cloud platform and multiple information systems (IS). The cloud platform mainly includes multiple high-performance servers. Through the cooperation among the elements of cyberspace and physical space, it can collect, organize, and analyze the data collected by the ISs, and virtualize all the resources in the MC-SIOT into services. The ISs (belonging to different departments) cover all information system elements (e.g., mobile terminals, software, and personnel). On one hand, through the ISs, all departments cooperate and connect through the MC-SIOT system. They can access the system anytime and anywhere through the cloud platform, in order to realize information sharing. This will help to improve the phenomenon of information islands within the enterprise. Additionally, the IS of each department is independent; it has its own functions. These departments include the sales department, the R\&D department, and the manufacturing workshop: (1) Sales department-Through negotiation and transactions with customers, employees can obtain sales data and market feedback. By integrating them into the management of the product design process, the employees can help the enterprise to design products, based on customer desires and market alignment; (2) R\&D department-On one hand, designers can query the product opinions of the sales department, and design products by using computers to operate machines and equipment. On the other hand, they can provide decision support for the management of combinations of new products and existing products, as well as query the patent data of existing products in the market through the Internet. It is helpful to understand how products coexist for market portfolio management, and to effectively grasp the product design situation to carry out innovative research and development; and 
(3) Manufacturing workshop-Employees query the product production requirements of the R\&D department, then operate machines and equipment through a computer to produce products. Additionally, they can monitor the manufacturing equipment, in order to ensure their normal operations and to avoid equipment failure.

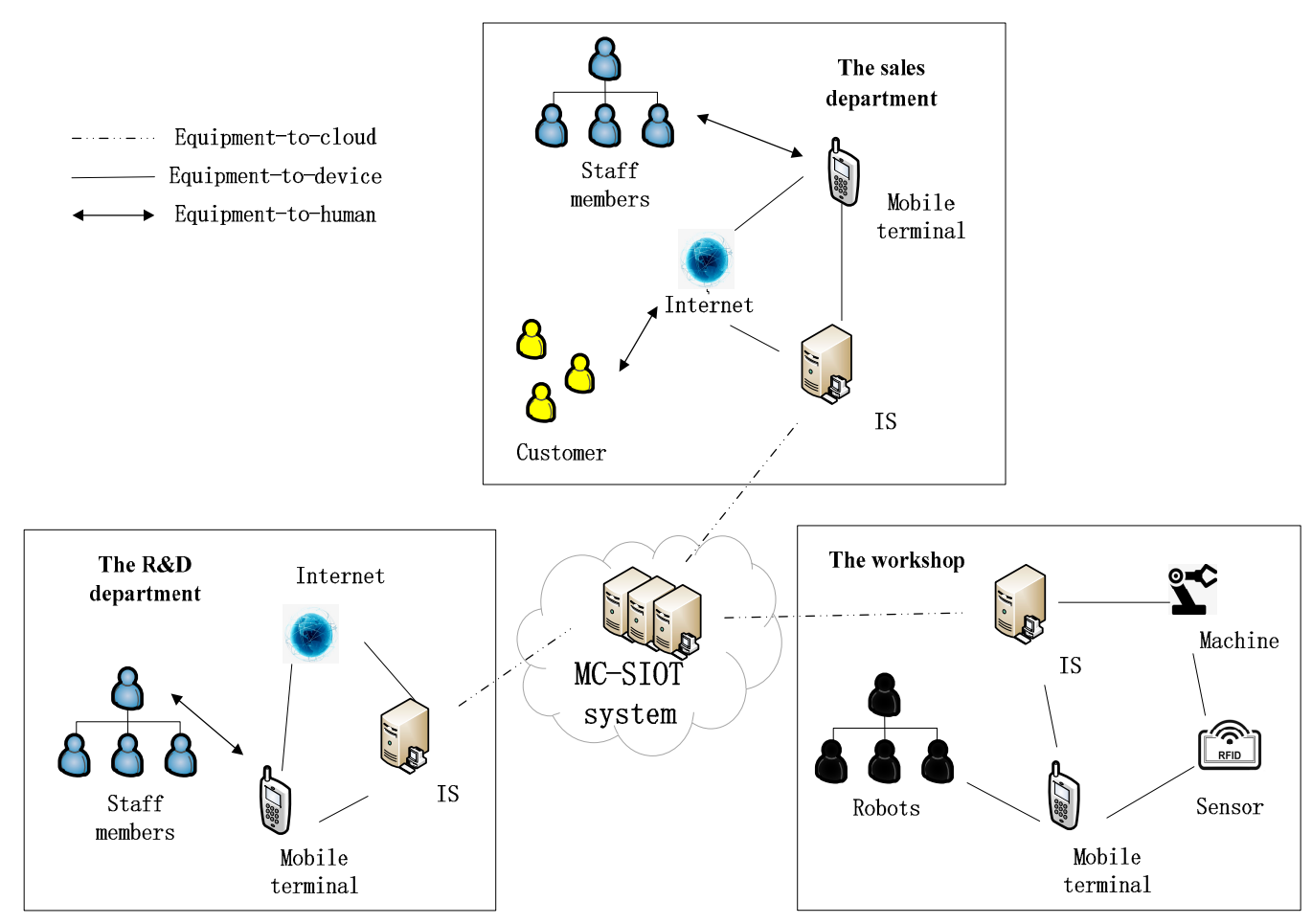

Figure 3. The organizational architecture of the MC-SIOT system.

According to the organizational analysis, in the MC-SIOT system, the information of each department will be transferred to the corresponding IS, and the database will be backed up and uploaded to the cloud platform. This can track the work progress in real-time, correct the deviations, and ensure product production efficiency.

\subsection{The Technical Architecture of MC-SIOT System}

A tremendous amount of real-time data are generated in the MC-SIOT system, where the growth of such data is beyond any previous estimate. Therefore, enterprises need to obtain data effectively and transform data into information through processing and analysis. Then, the information is extracted into knowledge. Finally, it further assists enterprise managers to make intelligent management decisions. This paper expounds on the technical structure of the MC-SIOT system from the perspective of the information value chain. As shown in Figure 4, the vertical conceptual framework of the MC-SIOT system can be divided into four levels: Data level, information level, knowledge level, and decision level. The bottom level is the data level, where the data may come from sensors, mobile terminals, customer opinions, patent libraries, and so on. These data are stored in the enterprise management system, and the enterprise status and customer status can be perceived offline (e.g., production line equipment) and online (website platform). This capability is rare in traditional MC systems. The second level is the information level. The data generated by the MC-SIOT system exceed the storage and computing capacities of traditional MC. Therefore, these data need to be extracted and analyzed, in order to find the information contained within them. A data scientist (a new role) appears at the information level, who uses various technologies to mine the corresponding information from the data. The third level is the knowledge level. According to the business needs, all staff will carry out further activities to extract valuable knowledge from the information through multidimensional analyses. Knowledge can be presented in various forms, such 
as reports and queries. The top level is the management level. With the help of data scientists, enterprise managers can make corresponding real-time management decisions based on the knowledge acquired. Additionally, new requirements will be generated in the implementation of decision making. In the meanwhile, the bottom layer will continue to collect new data.

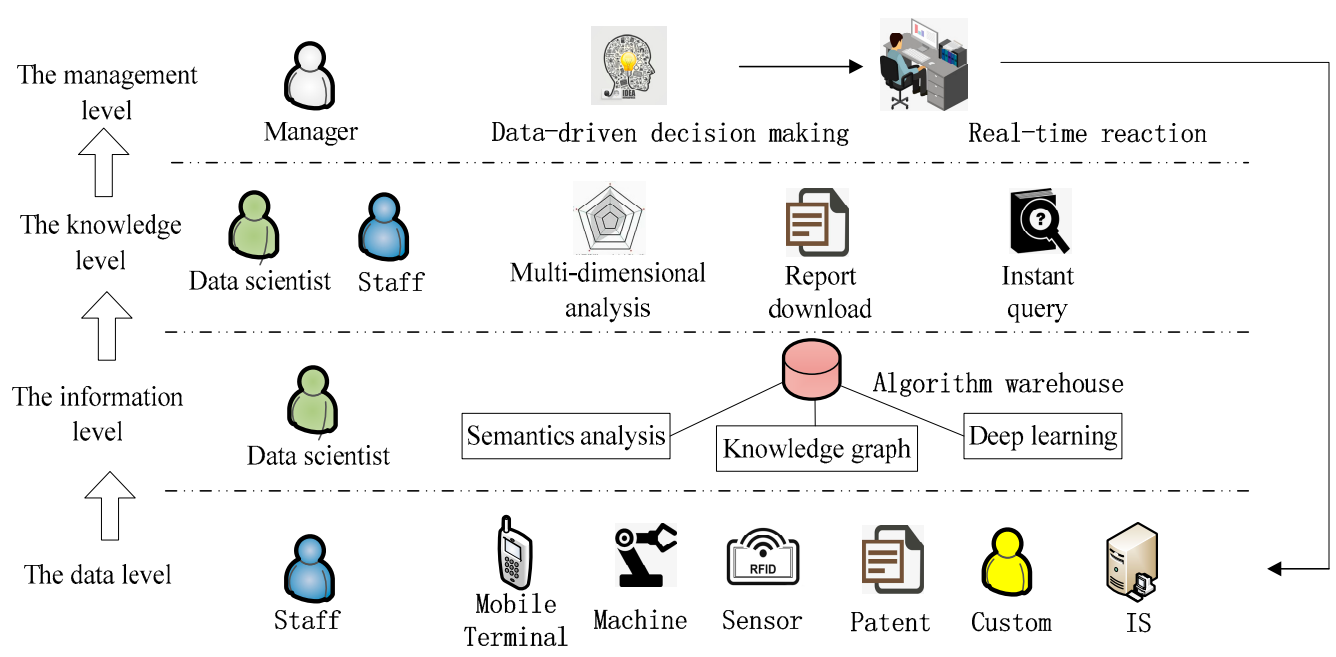

Figure 4. The technical architecture of the MC-SIOT system.

According to the technical analysis, the MC-SIOT system is based on a data-driven scientific decision-making management model. In this way, enterprises can handle massive amounts of data and transform them into important knowledge. This knowledge can be used to help entrepreneurs make decisions in a timely manner.

In summary, the overall architecture of the MC-SIOT system is shown in Figure 5. The organizational architecture contains three parts-the sales department, the R\&D department, and the workshop-while the technical architecture contains four parts-the data level, the information level, the knowledge level, and the management level.

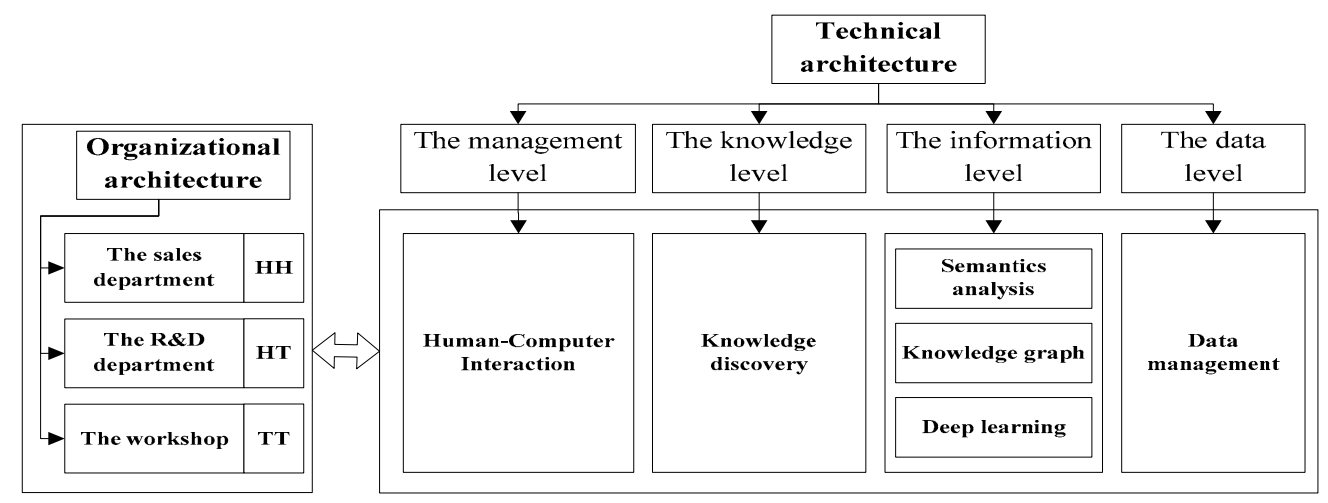

Figure 5. The overall architecture of the MC-SIOT system.

\section{Main Technological Applications}

The MC-SIOT architecture integrates many technologies, as shown in Figure 5. In this section, we elaborate on the main application scenarios, including semantic analysis, knowledge graph, and deep learning.

\subsection{Human-to-Human: Semantic Analysis}

Due to the various product information released by enterprise personnel, it is difficult for customers to find the products they need. At the same time, employees cannot quickly 
process online customer reviews. This makes it difficult for employees to communicate effectively with customers. In the MC-SIOT system, engineers can use semantic analysis technology to process the data of online reviews collected by the system, which can help employees to understand the potential opinions of customers and better enable employees to interact with customers. Semantic analysis [60] provides a way to extract features from text and vectorizing them, in order to represent text information with vector data. In other words, semantic analysis transforms the text content of an unstructured original text into structured data that can be recognized by a program.

As a new means of word-of-mouth communication, online reviews break the temporal and spatial restrictions of traditional word-of-mouth communication based on interpersonal diffusion. It enables potential consumers to improve their cognition of products by reading reviews [61-63], and assists them in making purchase decisions [64]. Therefore, online reviews are considered, in both academia and industry, as one of the key factors influencing consumer purchasing intentions and, thus, product sales [65]. Reasonable use of semantic analysis technology to extract user views from online reviews can not only help enterprises understand the needs of customers, but can also help enterprises to improve the quality of their products and services.

Promotion of sales-Numerous studies have shown that online reviews are related to product sales [66-69], including those related to tea [70], movies [71], and electronic products [72]. The content of online reviews can reflect a consumer's deep understanding of and detailed experience with the product, which often indirectly reflects the reasons why the product is loved by users [73]. Additionally, as the customer's sentiments are reflected in the online review, on one hand, it is the unique cognitive evaluation of the product by a consumer who has purchased the product and, as such, can provide useful clues to the impressions of potential consumers [74,75]. On the other hand, it has the effect of emotional contagion. Old users pass their feelings about the product on to potential new users through positive or negative evaluations. Reviews affect the emotions of potential customers [76]; for example, Banerjee et al. [77] have shown that the emotional content of online reviews plays a very important role in building reputation and building mutual trust between buyers and sellers. Lee et al. [78] used text mining technology to extract comment emotion coefficients and further studied how online reviews affect product sales. Additionally, online reviews can provide customers with real-time recommendations and marketing services [79-81].

Promotion of R\&D-With the increasingly abundant market supply, the personalized demands of consumers have become a new competitive focal point of enterprises. Consumer reviews are an important source of enterprise $R \& D$ [82]. The success of enterprise R\&D has become more and more closely related to the accurate analysis and prediction of consumer demands [83-86]. Consumers are regarded as innovative individuals or groups, which not only provide valuable information sources and creative designs for enterprise R\&D [87], but also have the willingness and ability to co-create R\&D value with enterprises $[88,89]$. Big data technology can improve the visualization of consumer participation behavior, making the data generated highly accessible and of high commercial value [90]. Therefore, enterprises can generate product ideas according to the mining of consumer needs, thus forming new products that better match the needs of consumers [91].

\subsection{Human-to-Thing: Knowledge Graph}

When the R\&D department carries out product innovation, it needs to expend a lot of human resources to deal with cutting-edge technical information (possibly related to patents). If there is no effective way to obtain technical information, enterprises lack the ability to carry out internal and external product innovation in a timely manner. In the MC-SIOT system, engineers can use knowledge graph technology to process the collected cutting-edge technical information. The system presents technical information to employees in a concise, visual manner. This can help employees find key technologies more efficiently, as well as enabling them to interact with the system efficiently. A knowledge 
graph [92] is a method of integrating scattered knowledge and visualizing its potential internal structure with advanced information technology and statistics. It takes scientific knowledge as the object and graphically expresses the relationships between the development process and structure of scientific knowledge. In other words, the construction of a complex knowledge network reveals the dynamic development law of knowledge in a visual form.

The number of existing patents is huge, and their relationships are contained in a semi-structured, high-dimensional knowledge unit relationship. Therefore, it is necessary to use knowledge graphing and multidimensional scaling analyses to reduce the number of dimensions. Through the knowledge graph analysis of patents, enterprises can focus on the industrial technology's development trends, hot-spots, evolutionary path, and opportunities. These can provide technical development directions and a strategic basis for manufacturing enterprises.

As a strategic resource for enterprises, patents possess the characteristics of heterogeneity and scarcity, which can bring sustainable competitive advantages for enterprises. High-tech enterprises, in particular, have a higher demand for patents, but how to improve technological innovation through effective patent management is a practical problem faced by enterprises. Reasonable use of a patent knowledge graph method to explore new product R\&D hot-spots in the manufacturing field can improve the process of new product $R \& D$ and technology development. The patent is a vital index for measuring the R\&D investment and productivity of enterprises [93-95]. For enterprises, the goal of patent application and authorization is to protect R\&D achievements. This can provide technological competitiveness [96,97], allow an enterprise to create a new technological market [98], and provide more value [99]. In addition, a patent can effectively promote innovation among other enterprises, thereby forming a virtuous circle. At present, patent analysis is becoming more and more important in enterprise innovation activities [100]. Most scholars measure the innovation activity of enterprises through patents [101]. For example, Ginarte et al. [102] have used cross-border data to show that patent protection affects the innovativeness of enterprises. Li et al. [103] believe that patents have become the main force promoting the competitiveness of enterprises in emerging countries. Penin et al. [104] have pointed out that patents can promote product innovation in enterprises. Most enterprises use patents as a strategic tool for R\&D cooperation. For example, Ernst et al. [105] determined the adjustment of the R\&D department by assessing the impact of patent output on company revenue. Additionally, intellectual property has a very powerful impact on the competitiveness of the manufacturing industry [106], and patents are an important embodiment of intellectual property rights [107]. Manu et al. [108] pointed out that patents contribute to how companies improve their competitiveness and performance. Yong et al. [109] believed that patents have a positive impact on technological innovation. In the technological knowledge ecosystem, enterprises can not only perceive internally, but also search externally. Through searching and discovering existing patent knowledge, enterprises can design new products. In other words, the separation and reorganization of existing patent knowledge technology [110], through mining the connection strength between patent knowledge [111], can be used as a main R\&D strategy for enterprises.

\subsection{Thing-to-Thing: Deep Learning}

Equipment failure affects the production schedule of a product. Therefore, the equipment reliability prediction is particularly important. In the MC-SIOT system, engineers can use deep learning technology to process the information of various pieces of equipment. By training the systems with historical or synthetic fault information and the current condition information, the system can predict the failure times of the equipment. This ensures their proper operation and allows for efficient interactions between devices. Deep learning [112] enables machines to imitate human activities, in terms of solving many complex pattern recognition problems, and has contributed to the great progress witnessed recently in artificial intelligence technology. Deep learning techniques can discover distributed feature 
representations of data by combining low-level features to form more abstract high-level presentation attribute categories (or features).

Equipment reliability prediction is a very important segment in the industry, which directly affects the running time and work efficiency of the equipment. In order to avoid equipment downtime in the production process, equipment faults need to be identified and handled quickly; however, the information systems of small and medium-sized enterprises are often open and complex systems affected by many uncertain factors. Therefore, it is very important to use deep learning to explore the reliability of the MC-SIOT system.

The practical significance of equipment reliability prediction is to remind equipment managers and maintenance personnel to eliminate the hidden trouble quickly, such that the equipment can enter stable operations again. In the face of the complexity of complex systems, the diversity of data types, and dynamic operation environments, deep learning technology can be used to solve various related problems, such as deep reinforcement learning [113], deep transfer learning [114], the deep belief network [115], and convolution neural networks [116]. In this way, enterprises can achieve adaptive fault feature extraction, complete independent analysis, explore fault mechanisms, and obtain high-value results. For example, the operations of a large complex industrial system leads to the production of numerous monitoring data every day. With the increase in the amount of data, the requirements for the software, hardware, and computing time also increase [117]. On one hand, through offline batch processing [118-120], deep learning can mine valuable information from massive data to predict the reliability of equipment. On the other hand, through real-time stream processing [121-123], deep learning can resolve the complex and changeable operating conditions in order to monitor the equipment in real-time, thus ensuring timely maintenance. In both cases, deep learning methods extract fault feature representations and combine them with data- and knowledge-driven approaches. In this manner, equipment maintenance can be carried out more accurately and scientifically, thus ensuring their reliability [124]. From an economic point of view, accurate and effective predictions reduce equipment downtime, improve the utilization rate of the equipment, and ensure their continued use. For example, Hinton et al. [125] have proposed and discussed the use of deep learning. By using such techniques, the collected detection data could be transformed, and the fault features could be extracted adaptively without relying on a manual design. Qi et al. [126] have proposed a hierarchical fault diagnosis network using deep learning, and their results indicated that the expression of diagnosis results in this way is detailed and reliable. Tamilselvan et al. [127] have presented a fault diagnosis method based on deep learning. After the layered training of the whole network, the parameters are then fine-tuned by another algorithm. Compared with the traditional training model processing method, this method can more effectively and accurately solve the problem of feature extraction from multi-sensor heterogeneous data. Feng et al. [128] established a deep neural network model to realize intelligent fault diagnosis with massive amounts of data. This not only eliminates the dependence of traditional methods on signal processing technology and human experience, but also ensures that an enterprise can complete the expected tasks within the specified time, thus improving customer satisfaction and enterprise efficiency.

\section{Key Problems}

This section focuses on the key issues facing the MC-SIOT system, as shown in Figure 6. (1) Data resources are very important resources in management. At the data level, there are three problems: Data collection, data transmission, and data storage and queries. (2) Effective knowledge discovery helps managers make decisions. At the knowledge level, there are three problems: knowledge extraction, knowledge representation, and knowledge updating. (3) The success or failure of management depends on making effective decisions. At the management level, it mainly faces the problems of intelligence, efficiency, reliability, and availability. At the end of this section, the key issues are summarized (as shown in Figure 6) and future research directions are proposed. 


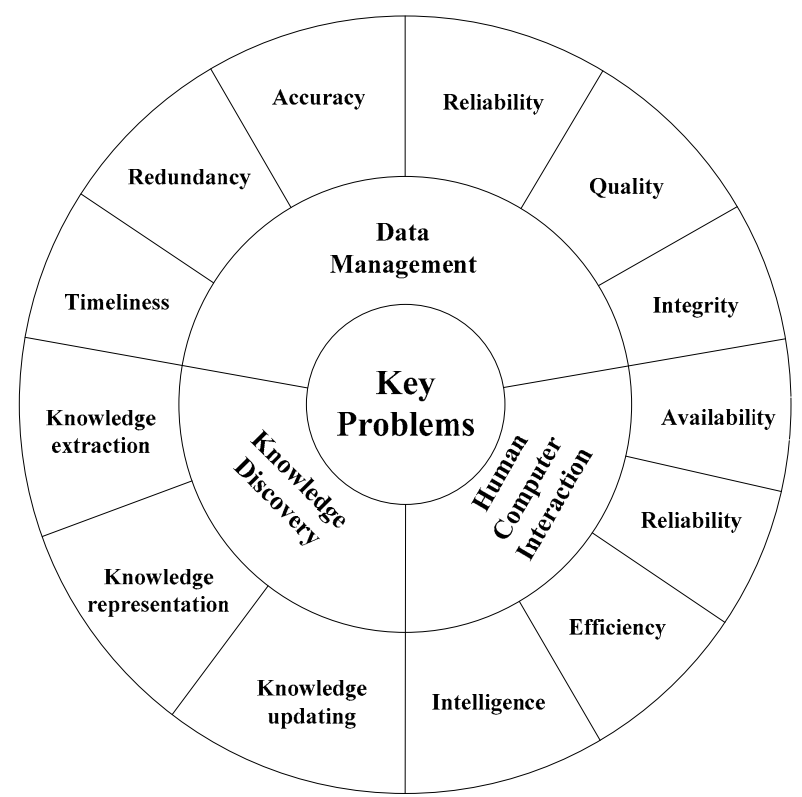

Figure 6. The key issues facing the MC-SIOT system.

\subsection{Data Management}

According to the horizontal framework of the MC-SIOT system, the data level of the MC-SIOT system involves multiple departments, where each department comprises independent equipment, terminals, machines, and operators to generate the corresponding data. Therefore, it is necessary for manufacturing enterprises to manage such data effectively, giving full play to the role of data. It includes data acquisition, data transmission, and data storage and query.

1. In terms of data collection, with the increasing application of intelligent equipment in manufacturing enterprises, manufacturing enterprises can obtain large amounts of data from intelligent devices and, thus, get rich data sets [129-131]; however, in the process of massive data collection, the following problems arise:

(1) In terms of integrity, as the intelligent manufacturing enterprise has many parts operating at the same time, its production equipment and control system need to run for a long time; that is to say, data will be generated at every moment and collected through the terminal for a long time. In the process of data acquisition over such a long period of time [132], it is very important to avoid missing important information, such as the important data relating to customer design or the fault data of production equipment. Therefore, ensuring normal operations is inseparable from the integrity of the data. In order to effectively detect whether the data are complete, it is necessary to label the data generated by all data sources.

(2) Ensuring data quality is an essential process $[133,134]$. Due to the different scenarios faced by the different departments of the MC-SIOT system in a manufacturing enterprise, the collected data cannot be of a unified specification and type, and the associated amounts of data are huge. It is difficult to ensure that the collected data are of high quality; that is, the collected data inevitably will contain invalid data (i.e., noise). Therefore, to ensure the quality of data, it is necessary to clean the data to ensure their integrity [135]. This can remove the noise contained in the data.

2. Data transmission usually refers to the process of transferring data from one place to another. Intelligent manufacturing enterprises produce a large amount of data, which are transmitted between devices through the wireless network [136,137]. This can effectively solve cross-organizational problems. Therefore, data transmission between 
manufacturing enterprises through large-scale wireless networks has become the norm. However, this involves the following problems:

(1) The reliability of a large-scale data network is very important for industrial production; however, packet loss is often inevitable in data transmission, which is one of the main reasons for errors in the process of data transmission. How to resolve the problem of packet loss and determining which data have been lost has been the focus of many studies. On one hand, a real-time data stream can be transmitted to the designated device within a specified time by coordinating the network [138], which can effectively reduce the packet loss rate in the process of data transmission [139]. This solution requires clearly understanding what data are transmitted (i.e., data annotation), in order to arrange the transmission channel for them. On the other hand, in case of an emergency, the transmitted data can be backed up and cached in a data buffer to avoid packet loss [140]. This solution also requires data annotation, in order to find the corresponding backup in the buffer immediately after the packet is lost.

(2) In terms of accuracy, the transmission system can connect the front and back terminals of the equipment to realize signal transmission. However, in the process of transmission, interference is very common, which causes the receiver to obtain the wrong information. Therefore, it is necessary to reasonably analyze whether there are interference factors during data transmission [141]. Particularly, one must ensure the functionality of transmitting and receiving information in a noisy environment [142]. When an error occurs, the system needs to effectively detect and correct the error; that is, it needs to accurately judge what the correct original code is, in order to ensure accurate data transmission. However, to judge the original code correctly, it is also necessary to label the original data.

3. Regarding data querying, the large amounts of data generated by manufacturing enterprises need to be stored, where the storage objects include the temporary files generated in the process of data flow or the information to be searched in the process. With the exponential growth of big data flows, data querying has also become more challenging [143]. The following problems are considered important:

(1) In current storage systems, there is high data redundancy. Repeated data input into the storage system occupies a significant amount of disk memory space. Therefore, duplicate data should be eliminated, in order to reduce the impact of meaningless data on storage [144], which is also convenient for data queries. In terms of timeliness, the system often takes a long time to obtain accurate query results [145]. Untimely information will be greatly reduced in usefulness, or may even have no value; that is, in some delay-sensitive applications, if it takes too long to answer a query, the query result(s) may become useless. Therefore, it is very important to satisfy the queries of users in a timely manner [146,147].

\subsection{Knowledge Discovery}

According to the vertical framework of the MC-SIOT system, the data resources in the database can be extracted and summarized in the knowledge base. Exploring hidden data plays a vital role in supporting decision making [148]. Therefore, effective knowledge management is the key problem of the MC-SIOT system, including knowledge extraction, knowledge representation, and knowledge updating.

1. In terms of knowledge extraction, there is an increasing demand for transforming raw data into knowledge, which is of great significance for decision making, optimization, and analysis [149-151]. Tang et al. [152] have proposed a method to acquire knowledge from documents, which can process documents with high complexity. 
However, the acquisition of expert knowledge is often a complex process involving a variety of activities [153]. Due to the diversity of domain experts, they often have different experiences and knowledge; that is, the information they can provide often has many types. Additionally, there are integrity and accuracy problems [154]. On the other hand, as knowledge has the characteristics of separation and dispersion, when employees transfer from one post to another, the problem of explicit and tacit knowledge acquisition and sharing cannot be ignored [155].

2. Knowledge representation refers to the association of knowledge factors and knowledge objects. It is convenient for people to recognize and understand knowledge. To date, many knowledge representation methods have been developed, including fuzzy rules [156,157]; however, most of them are static and cannot be adjusted dynamically. Liu et al. [158] have proposed an adaptive fuzzy model, which can reflect the different experiences of experts and realize knowledge reasoning dynamically. Jong et al. [159] have proposed temporal knowledge representation and reasoning technology. Considering heterogeneous data, Kargin et al. [160] have proposed an intelligent rule engine model which realized the cognitive functions of data generalization and abstraction, while Ebrahimipour et al. [161] have proposed a knowledge representation method based on ontology. This method can address the problems related to noise data, data arrangement, and ambiguous technical vocabulary in text maintenance records.

3. Knowledge updating means that a system can continuously learn new knowledge from new samples, while retaining most of the previously learned knowledge, which is similar to how human learning works. At present, with the emergence of incremental industrial big data, traditional static learning methods struggle to obtain incremental features effectively [162]. Therefore, incremental learning has become a new research hotspot. Incremental learning can make full use of the historical training results, such that the system can learn independently to adjust the relevant set value [163]. This reduces the need for manual interventions and adjusts key model parameters based on historical experience [164]. Additionally, incremental learning enables the system to perceive the surrounding environment [165] and take appropriate actions against the changes in the process [166]. By learning experience in the environment, it can improve its overall performance in unknown scenes [167]. This even makes the machine run automatically in cases of communication delay and unexpected system stoppage [168]. In addition to serving the normal operations of a system in various complex environments, incremental learning can also reduce the configuration time and expense, as configuration normally requires professional knowledge.

\subsection{Human-Computer Interaction}

Most information systems involve human-computer interaction (HCI). Therefore, $\mathrm{HCI}$ has become a key component of any complex system [169], and has become one of the key parts of intelligent manufacturing management $[170,171]$. According to the vertical framework of the MC-SIOT system, the managers can make real-time decisions through $\mathrm{HCI}$ at the management level.

1. In terms of intelligence, the system should have the function of capturing information or learning new knowledge for users. By distinguishing the levels of understanding of users, it can establish a harmonious relationship or sense of harmony, ensuring the comfort and participation of users. Xia et al. [172] have connected emotional design with interactive design, allowing the interactive design to shift from machinebased design to human-oriented design, in order to realize the unity of humans and objects. Erol et al. [173] expected that agents will recognize human emotional states to promote the natural connection between humans and robots. In addition, robots have been widely used in the industrial field. They usually perform complex tasks along with other robots and humans, promoting efficiency and accuracy while ensuring the 
safety of workers. Additionally, systems can combine semi-autonomous robots, edge computing, and cloud services to realize the automation of complex tasks [174].

2. In terms of efficiency, an HCI system can reduce the workload of human supervisors [175]. For example, Doering et al. [176] have proposed an imitation learning technology which learns the interactive behavior of social robots from natural HCI data. However, it only requires the designer to input minimal information. Liu et al. [177] found that the design of a $\mathrm{HCI}$ detection scheme is conducive to the system management, in terms of microdata and macro-control. This not only reduces the labor cost and improves the calculation speed, but also lays a solid foundation for the development of future technology. Furthermore, computer-aided design based on HCI technology can enhance the efficiency of industrial production [178]. Feng et al. [179] have introduced an $\mathrm{HCI}$ interface design method based on context awareness. It is very important to improve the efficiency of the system by improving the user's performance and satisfaction. Quintas et al. [180] have enhanced the interaction function by integrating a context and interaction information model into a decision model. This decision model acts as a supervisory process to control the interaction, allowing for more natural and effective interactions between human and artificial agents.

3. Reliability in $\mathrm{HCI}$ is very important for industrial production. Herrera et al. [181] have proposed a new fuzzy logic method. By integrating social rules into walking events, this method can overcome many common interference situations and adapt to different interference events over time. $\mathrm{Xu}$ et al. [182] have designed a machineoriented proximity estimation algorithm to simplify data connection, ensure data connection accuracy, and reduce the time complexity. Bowyer et al. [183] have designed an n-dimensional dissipative control strategy which can reduce the task error, thus enabling human-machine interactions to occur safely and effectively.

4. Availability is an important factor that must be considered when evaluating the operation of a system. By making the interaction process between users and devices simpler and easier, the system should become more available [184,185]. Additionally, availability is an important factor for users to achieve effectiveness, efficiency, and satisfaction within a specific environment $[186,187]$. Considering availability issues in the design of management applications can affect the user experiences of staff. Hu et al. [188] believed that the user should be central in the interactive design, in order to achieve a user-centered, reassuring, and user-satisfactory human-computer interface. Meng et al. [189] believed that user-centered design is the best way to create a usable human-computer interface, which can support operator tasks. To improve the usability of the HCI interface, Zeng et al. [190] have developed a comprehensive evaluation hierarchy of software and hardware interfaces, a corresponding comprehensive evaluation carrier, and a decision pattern.

Based on the three key issues described above, we summarize some challenges faced by the existing research and put forward several research directions for the future in Table 2. 
Table 2. A summary of current research challenges and future research directions.

\begin{tabular}{|c|c|c|}
\hline \multirow{3}{*}{ Data management } & Key problems & $\begin{array}{l}\text { 1. Integrity; 2. Quality; 3. Reliability; 4. Accuracy; 5. Redundancy; } \\
\text { 6. Timeliness }\end{array}$ \\
\hline & Challenges & $\begin{array}{l}\text { To solve the problem of incomplete data annotation and heterogeneous data } \\
\text { noise, how to ensure the anti-noise and realize perception of data }\end{array}$ \\
\hline & Future directions & $\begin{array}{l}\text { 1. Transfer learning: This technology can annotate and effectively manage the } \\
\text { data, including removing noise, avoiding packet loss, and fast searching } \\
\text { aspects.2. Digital twin: This technology can simulate and simulate the } \\
\text { operations of the system in the virtual space and exchange information with } \\
\text { the real world. Improve the reliability of system operation data. }\end{array}$ \\
\hline \multirow{3}{*}{ Knowledge discovery } & Key problems & $\begin{array}{l}\text { 1. Knowledge extraction; } 2 . \text { Knowledge representation; } \\
\text { 3. Knowledge updating }\end{array}$ \\
\hline & Challenges & $\begin{array}{l}\text { To solve the problem of information characteristics in complex environment; } \\
\text { how to carry out online knowledge updating of differentiated knowledge. } \\
\text { 1. Incremental learning: This technology is constantly learning new things } \\
\text { from new scenarios in the complex manufacturing environment. }\end{array}$ \\
\hline & Future directions & $\begin{array}{l}\text { 2. Reinforcement learning: This technique can be used to learn strategies to } \\
\text { achieve specific goals during interaction, ensuring the robustness of } \\
\text { the system. }\end{array}$ \\
\hline \multirow{3}{*}{ HCI } & Key problems & 1. Intelligence; 2. Efficiency; 3. Reliability; 4. Availability \\
\hline & Challenges & $\begin{array}{l}\text { To solve the problem of industrial scene understanding, human-computer } \\
\text { interface, and how to realize collaborative evolution and decision control } \\
\text { interaction through task collaboration. }\end{array}$ \\
\hline & Future directions & $\begin{array}{l}\text { The Multi-agent co-operative: This technology can help the system to realize } \\
\text { the scientific and efficient interaction of each body. }\end{array}$ \\
\hline
\end{tabular}

\section{The MC-SIOT System as a Complex System}

It can be understood that the MC-SIOT system is complex. Through the qualitative analysis of its complex system characteristics, we can obtain a deeper understanding of the MC-SIOT system. Additionally, we illustrate how to quantitatively reveal the behavior and evolutionary mechanism of the MC-SIOT system.

\subsection{Qualitative Analysis}

This system is composed of several sub-systems, which have the characteristics of multi-level structure, evolution, co-operation, self-similarity, self-organization, heterogeneity, and openness. These sub-systems interact through co-operative relationships. As enterprise systems are characterized by unpredictable, dynamic, and uncertain environments, researchers have advocated for the use of a complex system paradigm to clarify the bottom-up behavior of enterprise systems [191-193]. We describe the MC-SIOT system as a complex system. The details are as follows:

1. The MC-SIOT system has a multi-layered structure; each level reflects its upper-level components. For example, as shown in Figure 7, the first level node represents an MC-SIOT system, composed of the sales department (red), R\&D department (blue), and manufacturing workshop (green). The nodes of the second level represent the ISs of the sales department, R\&D department, and manufacturing workshop. In the third level, each node represents a sub-department; for example, the sales department is sub-divided into multiple stores, the R\&D department includes multiple product R\&D teams, and the manufacturing workshop includes multiple production lines. Sub-ISs exist in each ISs of the second level, and so on. This multi-level structure is the foundation of the MC-SIOT system.

2. The evolutionary strategy involves adapting to the external environment by adjusting the system's structure and components. For example, the MC-SIOT system can improve its IT infrastructure, business processes, management methods, and so on, according to a plan, in order to meet the needs of the enterprise market. 
3. The interactions of departments at the same level demonstrate the nature of the coordination. For example, the coordination and cooperation between ISs of different departments form a pull effect to promote the development of the MC-SIOT system.

4. Self-similarity refers to the repetitious structure of the MC-SIOT system and its components; for example, the MC-SIOT system contains multiple ISs of different departments, where the IS of each department comprises multiple modules. The self-similar structure is gradually formed in the process of evolution.

5. Self-organization refers to the spontaneous formation of new structures or behaviors through the adjustment of system components. When the enterprise plans to produce new products, the MC-SIOT system will automatically transfer the tasks to each department. After these departments receive their tasks, they will adjust their statuses voluntarily to complete the assigned tasks; for example, the sales department should find customer groups, the R\&D department may complete a product design demonstration, and the manufacturing workshop must ensure the timely production and delivery of products.

6. The MC-SIOT system is composed of multiple ISs, and there is a cooperative relationship between them. These ISs are based on a variety of architectures and achieve corresponding goals through different departments. Different departments are faced with different scenarios. The data are not only collected in a multi-source manner, but different devices in physical space or cyberspace are also used as the infrastructure.

7. The MC-SIOT system constantly exchanges resources and information with the surrounding environment; for example, the MC-SIOT system provides data related to products or services to consumers, while absorbing product innovation and workshop management experiences in the external environment. Due to its openness, the MC-SIOT system can be continuously upgraded.

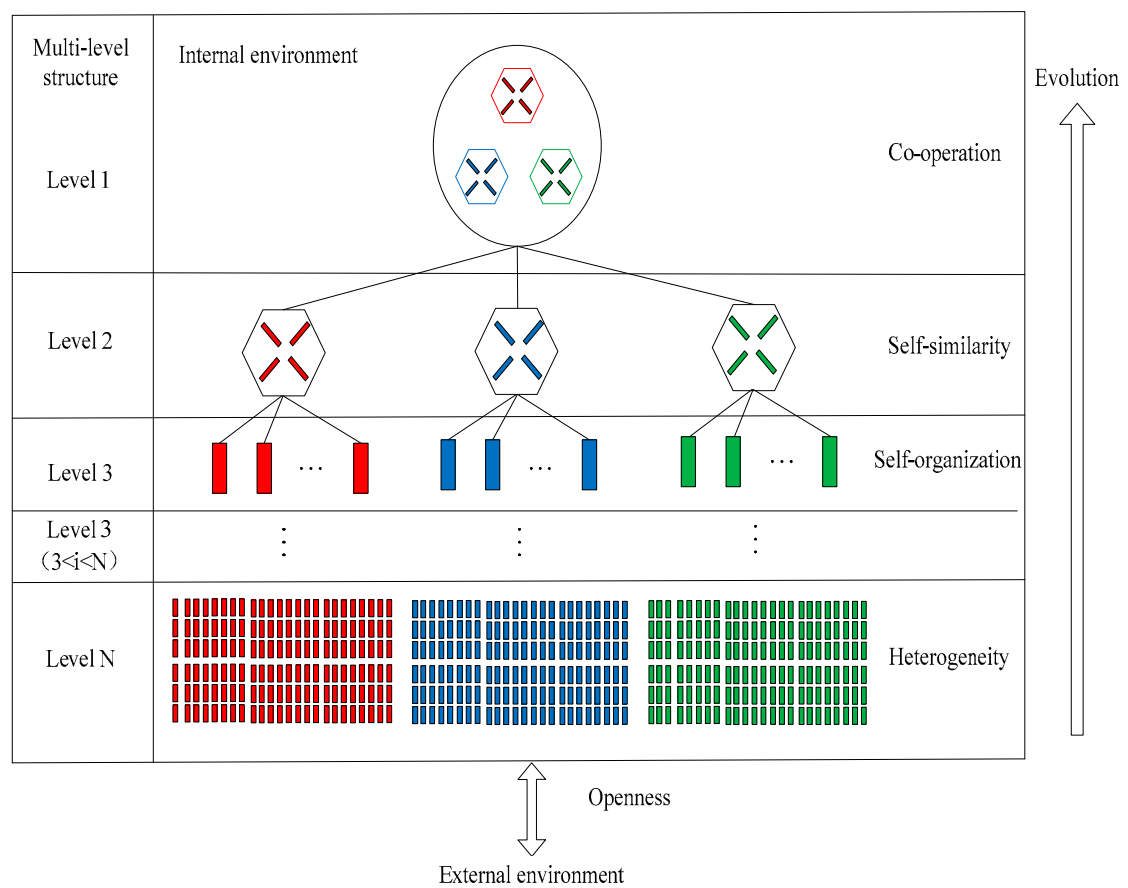

Figure 7. Qualitative analysis of the MC-SIOT system.

The qualitative description of the MC-SIOT system is depicted in Figure 7. Although the description is qualitative, it shows that the MC-SIOT system is a complex system. It is helpful to understand some of the more puzzling phenomena found in the MC-SIOT system. In addition, by providing the basic concept of a complex system, our interpretation provides the basis for quantitative description. 


\subsection{Quantitative Analysis}

The MC-SIOT system is composed of multiple heterogeneous units. Only through interaction can the overall function of the system be completed. This requires an information interface to transfer information between units and select interactive objects. In this way, the flexible coupling between units can be realized. In this paper, $\mathrm{R}-\mathrm{W}$ theory is applied to study the control performance of units.

(1) The state transition function

The calculation structure and state transition function of each unit were established such that the unit has autonomy during the operation of the MC-SIOT system, meets the system control requirements, and gives full play to its functions. The system unit model is as follows:

$$
H_{c}=\left(Q, \theta * \Sigma, \lambda_{c}, q_{0}, Q_{m}\right),
$$

where $Q$ is the state set, $\theta$ is the control mode set $(\theta=\{0,1\}), \Sigma$ is used for event collection, $\lambda_{c}$ is the state transition function, $q_{0}$ is the initial state, and $Q_{m}$ is the identification state (i.e., the work completion state).

It is assumed that the states in the set $Q=\left\{q_{0}, q_{1}, q_{2}\right\}$ for the equipment represent the standby state, working state, and fault state, respectively, while the components in the event set $\Sigma=\left\{\sigma_{1}, \sigma_{2}, \sigma_{3}, \sigma_{4}\right\}$ represent receiving instructions, work completion, failure, and troubleshooting, respectively. As the state of the unit of the system will change accordingly after an event, the above process can be represented by the state transition function. The state transition function can be defined as follows:

For $\forall q \in Q$, there are $\lambda(\varepsilon, q)=q, \lambda\left(\sigma_{2}, q_{2}\right)=q_{0}, \lambda\left(\sigma_{1}, q_{0}\right)=q_{1}, \lambda\left(\sigma_{3}, q_{1}\right)=q_{0}$, $\lambda\left(\sigma_{4}, q_{1}\right)=q_{2}$.

(2) Relationship between system units.

The MC-SIOT system needs to realize two-way information transmission between interactive units, such that the system is a two-way output interface of the octal group:

$$
M=\left(Q, \sum, \Delta, \lambda, \delta, q_{0}, F, B\right),
$$

where $Q$ is a non-empty finite set of states where, for $\forall q \in Q, q$ is a state calling $M$; $\Sigma$ is the input alphabet; $\mathrm{M}$ is any input string; $a \in \sum ; \Delta$ is the output alphabet; $\delta$ is the output function; $q_{0}$ is the start state of $\mathrm{M}$; $\mathrm{F}$ is the acceptance status set of $\mathrm{M}(F \subseteq Q)$; $\mathrm{B}$ is a Boolean character set $(B=\{0,1\})$; and $\lambda$ is the state transition function, such that $\lambda: Q * \sum * D \rightarrow Q * D$, where $D=\{L, R, S\}$ is the movement direction set. The specific explanations are as follows:

(1) If $\lambda(q, a, L)=\{p, L\}$, then if $M$ is in the state $q$, the character a is read, the state is changed to $p$, and then the character prior of a will be read. At this time, $\delta(p)=a$.

(2) When $\lambda(q, a, R)=\{p, R\}$, then $q$ in $M$ changes to $p$ after reading a, and the next character is then read.

(3) When $\lambda(q, a, S)=\{p, S\}$, the state of $M$ changes to $p$ after reading a, but the character is read again the next time.

In the latter two cases, when $p \neq q, \delta(p)=x$. When $p=q, \delta(p)=\varepsilon$, where $\varepsilon$ is a null character.

To realize the bi-directional information transmission function of the interface in the system, the system interface layer can be expressed as:

$$
\begin{gathered}
\{p[n], s\}=\lambda\left(p[n-1], y_{i}[n], d\right), \\
x_{i}[n]=\delta(d[n]),
\end{gathered}
$$

where $d \in D, p[n] \in Q, y_{i}[n] \in \sum ; \lambda$ is the output function $\lambda: \sum \rightarrow Q$, which maps discrete event variables to discrete time variables; and $\delta$ is the output function $\delta: \sum \rightarrow \Delta$, which maps discrete event variables to discrete time variables. Formula (3) indicates that 
the interface transmits the information of one unit to another unit and causes interactive unit events, while Formula (4) represents the interface conversion, which feeds back the state information of the interactive unit.

To clearly describe the mapping relationship, the mapping coupling function is constructed in this paper. The MC-SIOT system has mixed dynamic characteristics. Therefore, we assume that the attributes of all system units can be represented by events and states. The mapping coupling function is as follows:

$$
E_{a}=\psi\left(E_{r}, S_{r}, S_{a}\right),
$$

where $E_{a}$ and $S_{a}$ are the set of events and initial states of the target unit, respectively; and $E_{r}$ and $S_{r}$ are the event set and state set of the unit, respectively. For different interaction units, the mapping coupling function, $\psi$, has different specific forms.

In this paper, an ontology is used to establish the logical model of the system unit. Taking the equipment unit as an example, the Web Ontology Language (OWL) is used to establish the ontology structure of processing equipment based on semiotics:

$$
O_{m}:\left\{C, R, H^{c}, \operatorname{rel} A^{o}\right\}
$$

where $C$ is the collection of states and events, $R$ is the relationship set between its states and events, $H^{c}$ is the concept level (here, it is an empty set), rel is a specific function to realize the relationship between elements in $C$, and $A^{o}$ is the OWL language rule. On this basis, OWL can easily describe the attributes of a unit, in order to realize the semantic integration of the system through a reasonable integration structure. This ensures the smooth progress of the self-organization process of the system.

(3) Servo constraint function

The order parameter of the system is expressed by $P, P=\left(p_{1}, p_{2}, \ldots, p_{m}\right)$, where $p_{i}(i=1,2, \ldots, m)$ are the macro-order parameters of the system. Let the objective function be

$$
\begin{gathered}
A(n)=f[W(n), V(n)], \\
V(n)=g[P(n), E(n), B(n)],
\end{gathered}
$$

where $N$ is the servo time; $E$ and $B$ are information related to the order parameters in the environmental and feedback information, respectively; $V$ is the optimal state of the system under the action of order parameters; and $W$ is the weight corresponding to the order parameter in the servo action, $W=\left(w_{1}, w_{2}, \ldots, w_{m}\right)$. The weight relationship between different servo moments is given as follows:

$$
W(n+1)=\phi[W(n), A(n)] .
$$

To achieve the optimal state of the system, it is necessary to find the optimal value of $A(n)$. The optimization of $A(n)$ can be realized by the weight optimization algorithm. In this process, the interface is servo to the $\mathrm{F}$ function. By adjusting the interactive object and content of the system unit, according to $W$, the collaborative relationship of the system under the given goal is realized.

\section{Discussion}

Through the construction of the MC-SIOT framework, this paper should help system designers, as we have provided an advanced system which may address the key problems existing in such systems. We showed that the technologies involved in the MC-SIOT system mainly include three aspects: Semantic analysis, knowledge graphing, and deep learning. These technologies have different emphases and intersections. At the same time, these technologies face different problems, regarding data management, knowledge discovery, and HCI. This paper summarized the above content, in order to provide a reference for researchers. At the same time, given the problems existing in customer participation in 
production and process management as a whole, future research directions are put forward. These issues are discussed further in the following sections.

\subsection{Research Findings}

We showed that the intelligent manufacturing concept using the IOT has many valuable practices, which can be used for different purposes, such as R\&D and fault diagnosis; however, there is a lack of understanding regarding customer participation in decision making. Therefore, in this paper, we introduced SIOT into MC information systems to improve customer participation in $\mathrm{MC}$ and the management of enterprises. For example, customer demand analysis is necessary for $\mathrm{MC}$, which is the reason for the continuous development and rapid progression of semantic analysis. Through semantic analysis, customer opinions and needs can be captured through social networks. Based on the results, enterprises can understand the popularity of their products on the market. Therefore, enterprises should collect accurate data in real-time, in order to capture changes in customer needs. To collect these data, future research needs to develop enhanced artificial intelligence and special analysis algorithms, which can analyze and process multi-modal real-time data and generate dynamic customer knowledge graphs.

The MC-SIOT can be used as a platform to link and display all of the activities of MC in manufacturing enterprises; in addition, it is considered helpful to use AI algorithms for data mining. For example, the Paraimpu platform uses virtual services on Web pages and a social network framework to realize user addition, sharing, and interaction functions, in order to create personalized applications [194]. Further, the MUL-Swot platform provides users with Internet of Things service suggestions. It supports communication between users and third-party platforms by calling a Web API [195]. In the above system, the interactions between people and things are realized mainly in the form of natural language. Therefore, by collecting a large amount of text data and using an artificial intelligence algorithm for data mining, the MC-SIOT platform can realize user feature recognition, basic information queries, and user demand analysis. Based on user portraits, the user label database and user relationship database can be established to query the basic information. For example, designing distributed data management based on user portraits can provide a retrieval function. In the process of human-computer interaction, a user portrait can help the machine to understand the user's intentions more clearly and better answer the user's questions. It can continuously carry out index management and query optimization.

At present, support for patent analysis methods for enterprise technology prediction and decision making remains relatively weak. The identification of core technology vacancy and the evaluation of patent technology innovation can only provide a subjective reference for decision makers, in the form of static and historical data. Secondly, existing patent analyses often pay attention to a single piece of technology, while paying little attention to the technology's relevance and the dynamic evolution of technological groups. Therefore, using a knowledge graph algorithm for knowledge discovery in the MC-SIOT framework can realize patent link prediction, patent quantification, and visualization.

In the patent network of SIOT, each node represents a technical knowledge area and each link represents the dynamic amount of interaction between a pair of technical knowledge areas. In knowledge discovery, link prediction can predict the changing relationship between different technical knowledge fields. It can discover new products and future changes of existing products, based on patent documents. In terms of human-computer interaction, this can help enterprise R\&D personnel to determine the distribution of relevant technical knowledge.

Deep learning technology is data-driven, and its results are often limited by relevant data types and availability. However, in the real environment, equipment is often in a healthy state, such that it is difficult to obtain a large amount of comprehensive fault data. Therefore, in the framework of MC-SIOT, diagnostic technology and digital twin technology can be interconnected. This can not only simulate the physical entity of the device in the virtual space and use a large number of simulated device fault data sets, but 
the real device fault data can also be used to fine-tune the model, thus enabling effective information management. Additionally, in terms of human-computer interactions, the MC-SIOT system can diagnose and receive equipment status information. If the equipment status deviates from the preset range, the system can send a notification to the management personnel, reminding them to maintain the equipment.

\subsection{Limitations}

This paper introduced the use of different technologies, but these technologies have some problems. The relative details are as follows:

Intelligent technology relies heavily on large amounts of data, but a lack of highquality data may affect the operations of the associated systems. This challenge can be seen as twofold, due to: (1) A lack of data quality management technology; and (2) the amount of data being small and difficult to obtain. In short, the data source may have problems with relatively small total amounts and low data quality (e.g., affected by noisy and/or abnormal data). Therefore, it is necessary to further study the data processing methods to support the rational and efficient use of data by MC-SIOT.

There is still a lack of application of quantitative intelligent algorithms that have been trained with expert knowledge. At present, there are two difficulties inherent to knowledge discovery in a complex environment: (1) Due to the lack of dynamic knowledge, most of the existing systems provide static and historical data for the subjective reference of decision makers; and (2) such data require manual review by professionals, which means that a lot of resources are required to update knowledge.

It is necessary to solve the problem of task scheduling and coordination between humans and machines, especially in complex dynamic industrial scenes. Otherwise, there will be interface barriers and decision conflicts between the personnel and equipment.

\subsection{Future Directions}

Data quality management based on transfer learning: Based on manually labeling a small amount of data, information can be extracted from them through use of this technology and then used for target data. This method can label the data, and not only make up for the defects of different data feature distributions, but also effectively manage the data; for instance, removing noise, avoiding packet loss, and retrieval.

Digital twins can be used to solve the problems related to insufficient data samples. This technology not only can make up for a lack of training data, but also provide information for real-world models, making them very important in improving the reliability of system operation data.

Incremental learning carries out autonomous and unsupervised knowledge learning. This technology can constantly learn new things from new scenes in a complex manufacturing environment, taking the current new data as the input to add new knowledge to the existing knowledge graph. This technology can adjust the structure of the knowledge graph, accordingly.

Reinforcement learning adopts a continuous "interaction trial-and-error" mechanism to achieve specific goals in the process of interaction, ensuring the robustness of the system. By applying human domain knowledge and implicit experience to reinforcement learning, the system can obtain feedback information from specific situations, such that it can learn the optimal strategy to complete the task. This realizes the effective combination of quantitative algorithms and expert knowledge.

Multi-agent cooperation technology can help the system to realize scientific and efficient interactions among agents. It is a system formed of multiple independent agents to complete a complex task through local cooperation and interaction. It can allow people and machines to learn and adapt through their interactions with each other, and realize co-evolution and decision control interaction through task cooperation.

In addition, although not discussed in this paper, important research to be carried out in the future is as follows: First, we suggest conducting research into privacy protection. 
SIOT can provide feedback on its interactions with some IOT devices and users. However, this behavior can disclose the communication behavior between the device and the user [196]. Especially in the context of MC, users need to be highly involved in the product production process. Therefore, future MC-SIOT systems should adopt block-chain encryption technology to prevent illegal or malicious nodes from accessing private user data. We also suggest the development of emotional interaction technology. Whether intelligent devices cause psychological and emotional conflicts between users and employees has not yet been fully studied. The impacts of the intelligent environment on human psychology and emotion should be assessed, and the design of the MC-SIOT system should be adjusted to overcome the above problems.

In summary, this paper introduced the architecture of the MC-SIOT system and reviewed the related research. We found that the system is user-driven, in that user demand is the main concern, while the whole production process is the secondary concern. Recognizing the huge demand for user-centered systems, we integrated different technologies (i.e., semantic analysis, knowledge graph, deep learning) into this system, and analyzed various problems related to areas such as data management, knowledge discovery, and HCI. On this basis, future improvement directions were also proposed, and more research directions have been opened up, including privacy protection and system emotional interactions.

\section{Conclusions}

In this paper, we reviewed relevant research into IOT-based systems. According to the essence of IOT, we determined the relevant technologies involved, such as semantic analysis, knowledge graphs, and deep learning. These technologies face some key challenges, including data management, knowledge discovery, and human-computer interaction. However, traditional IOT cannot effectively manage customer data under the scenario of mass customization. Therefore, SIOT has become an emerging trend. Through the integration of social networks and the Internet of Things, SIOT extends human-human social relations to those between things and people, and things and things. This can effectively connect the network customer base with the enterprise. It not only allows customers to participate in the MC production process, but also allows enterprises to control all links through the whole information system.

The MC-SIOT system not only provides a way to introduce SIOT into the MC system, but also a means to promote business activities digitally. This can realize the conceptual transformation from manufacturing production to service production; however, the current technology and management level are not sufficiently advanced, which imposes limitations on the MC-SIOT system. To fully understand the current situation of the MC-SIOT system and lay the foundations for future research, we conducted study on the MC-SIOT. First, we introduced the architecture of the system from organizational and technological perspectives. Then, the key problems, challenges, and future development directions of the MC-SIOT system were discussed in detail. Finally, the MC-SIOT system was described in detail, from both qualitative and quantitative perspectives. This will further enable manufacturing enterprises to understand the MC-SIOT system, in order to pave the way for future promotion.

The specific findings of this paper are as follows: (1) The MC-SIOT system can be used as a platform to realize user feature recognition, basic information queries, and user demand analyses; (2) In the MC-SIOT framework, the knowledge graph algorithm is used for knowledge discovery. It not only can predict the relationships between knowledge fields, but can also help R\&D personnel to quantify the distribution of relevant technical knowledge; (3) The diagnosis technology and digital twin technology can be interconnected in the MC-SIOT system. By simulating the physical entity of the device in the virtual space, effective information management can be carried out.

However, these findings have some limitations and challenges: (1) The data sources may have the problems of the relatively small output and low data quality, which will affect the system's operation. (2) The application of quantitative intelligent models based 
on expert knowledge is still lacking. (3) In complex dynamic industrial scenarios, it is necessary to solve the problem of task scheduling and coordination between humans and machine within a limited time.

Therefore, we put forward some future research directions: (1) Transfer learning should be used to solve the defects of different data feature distributions and effectively manage data; (2) The digital twin method could solve the problem of insufficient data samples and improve the reliability of operation data; (3) Incremental learning should be used to learn new things from new scenes under complex manufacturing environments; (4) Reinforcement learning should be used to obtain feedback from specific situations, in order to realize effective combinations of quantitative algorithms and expert knowledge; (5) Multi-agent cooperation technology should be used to help the system to realize efficient cooperation and decision-making control interactions between humans and machines/computers throughout tasks. In addition, future research should consider privacy protection and emotional interactions.

Author Contributions: Writing — original draft preparation, Zixin Dou, Yanming Sun, Shiqi Fan and Yuxuan Zhang; writing - review and editing, Zixin Dou, Yanming Sun, Zhidong Wu and Tao Wang; resources, Tao Wang; supervision, Yanming Sun. All authors have read and agreed to the published version of the manuscript.

Funding: This research was funded by the National Natural Science Foundation Project under grant number 71571072; the National Social Science Foundation Project under grant number 18BGL236; the Guangdong Province Key Research and Development Project under grant number 2020B0101050001; and the Special Fund for Science and Technology Innovation Strategy of Guangdong Province under grant number pdjh2021b0405.

Institutional Review Board Statement: Not applicable.

Informed Consent Statement: Not applicable.

Data Availability Statement: Not applicable.

Acknowledgments: The authors thank the MDPI editor and anonymous reviewers for their numerous constructive comments and encouragement that have improved our paper greatly.

Conflicts of Interest: The authors declare no conflict of interest.

\section{References}

1. Mo, H.; Wagle, N.; Zuba, M. Cyber-physical systems. XRDS: Crossroads ACM Mag. Stud. 2014, 20, 8-9. [CrossRef]

2. Gershenfeld, N.; Krikorian, R.; Cohen, D. The Internet of Things. Sci. Am. 2004, 291, 76-81. [CrossRef] [PubMed]

3. Apte, C. Data mining: An industrial research perspective. IEEE Comput. Sci. 1997, 4, 6-9. [CrossRef]

4. Lasi, H.; Fettke, P.; Kemper, H.; Feld, T.; Hoffmann, M. Industry 4.0. Bus. Inf. Syst. Eng. 2014, 6, 239-242. [CrossRef]

5. Wang, Y.; Ma, H.; Yang, J.; Wang, K. Industry 4.0: A way from mass customization to mass personalization production. Adv. Manuf. 2017, 5, 311-320. [CrossRef]

6. Hao, T.; Chen, C.; Cheng, F.; Yang, H. Automatic Virtual Metrology and Target Value Adjustment for Mass Customization. IEEE Robot. Autom. Lett. 2017, 2, 546-553.

7. Dyk, D.; Pretorius, L. A system dynamics approach to quality improvement programs in a heavy engineering manufacturing environment: A case study. In Proceedings of the PICMET 2012: Technology Management for Emerging Technologies, Vancouver, BC, Canada, 29 July-2 August 2012; pp. 3287-3296.

8. El Hadj Khalaf, R.; Agard, B.; Penz, B. Module selection and supply chain optimization for customized product families using redundancy and standardization. IEEE Trans. Autom. Sci. Eng. 2011, 8, 118-129. [CrossRef]

9. Davis, S. From "future perfect": Mass customizing. Strategy Leadersh. 2013, 17, 16-21. [CrossRef]

10. Silveira, G.; Fogliatto, F.; Fendyur, A. Demographics of mass customization: A global study of manufacturing plants. Production 2016, 26, 1-11. [CrossRef]

11. Mindas, M.; Bednar, S. Mass Customization in the Context of Industry 4.0: Implications of Variety-induced Complexity. In Advanced Industrial Engineering: Industry 4.0; Springer: Amsterdam, The Netherlands, 2016; Chapter 2.

12. Iarovyi, S.; Lastra, J.; Haber, R.; Toro, R. From artificial cognitive systems and open architectures to cognitive manufacturing systems. In Proceedings of the 2015 IEEE 13th International Conference on Industrial Informatics (INDIN), Cambridge, UK, 1 October 2015; pp. 1225-1232.

13. Da Cunha, C.; Agard, B.; Kusiak, A. Design for Cost: Module-Based Mass Customization. IEEE Trans. Autom. Sci. Eng. 2007, 4, 350-359. [CrossRef] 
14. Michael, N. Mass Customization: The New Frontier in Business Competition: B. Joseph Pine II; Harvard Business School Press: Brighton, MA, USA, 1993; p. 142.

15. Partanen, J.; Haapasalo, H. Fast production for order fulfillment: Implementing mass customization in electronics industry. International Journal of Production Economics. Int. J. Prod. Econ. 2004, 90, 213-222. [CrossRef]

16. Lu, R.; Petersen, T.; Storch, R. Asynchronous stochastic learning curve effects in engineering-to-order customisation processes. Int. J. Prod. Res. 2009, 47, 1309-1329. [CrossRef]

17. Mike, B. Innovation in the Food Industry: Personalised Nutrition and Mass Customisation. Innovation 2008, 10, 53-60.

18. Barlow, J.; Childerhouse, P.; Gann, D.; Hong-Minh, S.; Naim, M.; Ozaki, R. Choice and delivery in housebuilding: Lessons from Japan for UK housebuilders. Build. Res. Inf. 2003, 31, 134-145. [CrossRef]

19. Song, Z.; Sun, Y.; Wan, J.; Huang, L.; Zhu, J. Smart e-commerce systems: Current status and research challenges. Electron. Mark. 2017, 29, 221-238. [CrossRef]

20. Abdel-Aal, M.; Selim, S. Risk-averse multi-product selective newsvendor problem with different market entry scenarios under CVaR criterion. Comput. Ind. Eng. 2017, 103, 250-261. [CrossRef]

21. Verma, P. Assessment of pre and post-disaster supply chain resilience based on network structural parameters with CVaR as a risk measure. Int. J. Prod. Econ. 2020, 227, 107655.

22. Gang, W.; Gunasekaran, A.; Ngai, E.; Papadopoulos, T. Big data analytics in logistics and supply chain management: Certain Investigations for research and applications. Int. J. Prod. Econ. 2016, 176, 98-110.

23. Larrea, G.; Gregory, A. Informing timeshare exchange services on the drivers of customer-driven co-production. Int. J. Hosp. Manag. 2020, 91, 102645. [CrossRef]

24. Liu, J.; Chang, H.; Forrest, Y.; Yang, B. Influence of artificial intelligence on technological innovation: Evidence from the panel data of china's manufacturing sectors. Technol. Forecast. Soc. Chang. 2020, 158, 120142. [CrossRef]

25. Iera, A.; Morabito, G.; Atzori, L. The Social Internet of Things. In Proceedings of the 2015 IEEE International Conference on Cloud Engineering (IC2E), Tempe, AZ, USA, 9-13 March 2015; p. 1.

26. Nemeschansky, B.; Heidt, T.; Kim, P. Customer-driven menu analysis (CDMA): Capturing customer voice in menu management. Int. J. Hosp. Manag. 2019, 91, 102417. [CrossRef]

27. Nitti, M.; Girau, R.; Atzori, L. Trustworthiness Management in the Social Internet of Thing. IEEE Trans. Knowl. Data Eng. 2014, 26, 1253-1266. [CrossRef]

28. Chen, Y.; Tao, Y.; Zheng, Z.; Chen, D. Graph-based service recommendation in Social Internet of Things. Int. J. Distrib. Sens. Netw. 2021, 17, 1477-1550. [CrossRef]

29. Son, J.; Choi, W.; Choi, S. Trust information network in social Internet of things using trust-aware recommender systems. Int. J. Distrib. Sens. Netw. 2020, 16, 12. [CrossRef]

30. Huang, L.; Dou, Z.; Hu, Y.; Huang, R. Textual Analysis for Online Reviews: A Polymerization Topic Sentiment Model. IEEE Access 2019, 99, 91940-91945. [CrossRef]

31. Cascini, G.; Russo, D. Computer-aided analysis of patents and search for TRIZ contradictions. Int. J. Prod. Dev. 2007, 4, 52-67. [CrossRef]

32. Zhu, J.; Gong, Z.; Sun, Y.; Dou, Z. Chaotic neural network model for SMISs reliability prediction based on interdependent network SMISs reliability prediction by chaotic neural network. Qual. Reliab. Eng. Int. 2020, 37, 717-742. [CrossRef]

33. Sepasgozar, S.; Karimi, R.; Farahzadi, L.; Moezzi, F.; Shirowzhan, S.; Ebrahimzadeh, S.M.; Hui, F.; Aye, L. A Systematic Content Review of Artificial Intelligence and the Internet of Things Applications in Smart Home. Appl. Sci. 2020, 10, 3074. [CrossRef]

34. Alzahrani, S. Development of IoT mining machine for Twitter sentiment analysis: Mining in the cloud and results on the mirror. In Proceedings of the 2018 15th Learning and Technology Conference (L\&T), Jeddah, Saudi Arabia, 25-26 February 2018; pp. 86-95.

35. Htet, H.; Khaing, S.; Yi, Y. Tweets Sentiment Analysis for Healthcare on Big Data Processing and IoT Architecture Using Maximum Entropy Classifier. Big Data Anal. Deep. Learn. Appl. 2018, 28-38. [CrossRef]

36. Psomakelis, E.; Aisopos, F.; Litke, A.; Tserpes, K.; Kardara, M.; Campo, P. Big IoT and social networking data for smart cities: Algorithmic improvements on Big Data Analysis in the context of RADICAL city applications. arXiv 2016, arXiv:1607.00509.

37. Liu, Y.; Du, F.; Sun, J.; Jiang, Y.; He, J.; Zhu, T.; Sun, C. A crowdsourcing-based topic model for service matchmaking in Internet of Things. Future Gener. Comput. Syst. 2018, 87, 186-197. [CrossRef]

38. Bermudez-Edo, M.; Elsaleh, T.; Barnaghi, P.; Taylor, K. IoT-Lite: A Lightweight Semantic Model for the Internet of Things. In Proceedings of the 2016 IEEE Conferences on Ubiquitous Intelligence \& Computing, Advanced and Trusted Computing, Scalable Computing and Communications, Cloud and Big Data Computing, Internet of People, and Smart World Congress, Toulouse, France, 18-21 July 2016; pp. 90-97.

39. Liu, F.; Ping, L.; Deng, D. Device-Oriented Automatic Semantic Annotation in IoT. J. Sens. 2017, 2017, 1-14. [CrossRef]

40. Xie, C.; Yu, B.; Zeng, Z.; Yang, Y.; Liu, Q. Multi-Layer Internet of Things Middleware based on Knowledge Graph. IEEE Internet Things J. 2020, 8, 2635-2648. [CrossRef]

41. Gómez-Berbís, M.; Amescua-Seco, A. SEDIT: Semantic Digital Twin Based on Industrial IoT Data Management and Knowledge Graphs. In Proceedings of the Technologies and Innovation, 5th International Conference, CITI, Guayaquil, Ecuador, 2-5 December 2019.

42. Khokhlov, I.; Reznik, L. Knowledge Graph in Data Quality Evaluation for IoT applications. In Proceedings of the 2020 IEEE 6th World Forum on Internet of Things (WF-IoT), New Orleans, LA, USA, 3 November 2020; pp. 1-6. 
43. Li, Q.; Cao, Z.; Tanveer, M.; Pandey, H.; Wang, C. A Semantic Collaboration Method Based on Uniform Knowledge Graph. IEEE Internet Things J. 2020, 7, 4473-4484. [CrossRef]

44. Liu, W.; Yin, L.; Wang, C.; Liu, F.; Ni, Z. Medical Knowledge Graph in Chinese Using Deep Semantic Mobile Computation Based on IoT and WoT. Wirel. Commun. Mob. Comput. 2021, 2021, 1-13.

45. Karim, F.; Naameh, O.; Lytra, I.; Mader, C.; Vidal, M.; Auer, S. Semantic Enrichment of IoT Stream Data On-demand. In Proceedings of the 2018 IEEE 12th International Conference on Semantic Computing (ICSC), Laguna Hills, CA, USA, 31 January-2 February 2018; pp. 33-40.

46. Yao, J.; Jiang, X.; Wang, S.; Jiang, K.; Yu, X. SVM-BiLSTM: A Fault Detection Method for the Gas Station IoT System Based on Deep Learning. IEEE Access 2020, 8, 203712-203723.

47. Hou, R.; Zhao, Y.; Tian, S.; Yang, Y.; Yang, W. Fault point detection of IOT using multi-spectral image fusion based on deep learning. J. Vis. Commun. Image Represent. 2019, 64, 102600.1-102600.8. [CrossRef]

48. Benkedjouh, T.; Zerhouni, N.; Rechak, S. Deep Learning for Fault Diagnosis based on short-time Fourier transform. In Proceedings of the 2018 International Conference on Smart Communications in Network Technologies (SaCoNeT), El Oued, Algeria, 27-31 October 2018; pp. 288-293.

49. Zhang, C.; He, Y.; Du, B.; Yuan, L.; Li, B.; Jiang, S. Transformer fault diagnosis method using IoT based monitoring system and ensemble machine learning. Future Gener. Comput. Syst. 2020, 108, 533-545. [CrossRef]

50. Chen, F.; Fu, Z.; Yang, Z. Wind power generation fault diagnosis based on deep learning model in internet of things (IoT) with clusters. Clust. Comput. 2018, 22, 14013-14025. [CrossRef]

51. Li, F.; Wu, J. MOPS: Providing Content-Based Service in Disruption-Tolerant Networks. In Proceedings of the 2009 29th IEEE International Conference on Distributed Computing Systems, Montreal, QC, Canada, 22-26 June 2009; pp. 526-533.

52. Jung, J.; Chun, S.; Jin, X. Enabling smart objects discovery via constructing hypergraphs of heterogeneous IoT interactions. J. Inf. Sci. Princ. Pract. 2018, 44, 110-124. [CrossRef]

53. Qureshi, B.; Min, G.; Kouvatsos, D.; Ilyas, M. An Adaptive Content Sharing Protocol for P2P Mobile Social Networks. In Proceedings of the 2010 IEEE 24th International Conference on Advanced Information Networking and Applications Workshops, Perth, Australia, 20-23 April 2010; pp. 413-418.

54. Qiu, T.; Luo, D.; Xia, F.; Deonauth, N.; Si, W.; Tolba, A. A greedy model with small world for improving the robustness of heterogeneous Internet of Things. Comput. Netw. 2016, 101, 127-143. [CrossRef]

55. Kang, D.; Choi, J.; Jung, J.; Kang, K.; Bae, C. SDIF: Social device interaction framework for encounter and play in smart home service. IEEE Trans. Consum. Electron. 2016, 62, 85-93. [CrossRef]

56. Lee, H.; Kim, K.; Kwon, J. A Pervasive Interconnection Technique for Efficient Information Sharing in Social IoT Environment. Int. J. Smart Home 2016, 10, 9-22. [CrossRef]

57. Turcu, C.; Turcu, C. The Social Internet of Things and the RFID-based robots. In Proceedings of the 2012 IV International Congress on Ultra-Modern Telecommunications and Control Systems, St. Petersburg, Russia, 3-5 October 2012; pp. 77-83.

58. Agostinho, C.; Ducq, Y.; Zacharewicz, G.; Sarraipa, J.; Lampathaki, F. Towards a sustainable interoperability in networked enterprise information systems: Trends of knowledge and model-driven technology. Comput. Ind. 2016, 79, 64-76. [CrossRef]

59. Liang, P.; Sun, Y.; Li, W. Service-oriented manufacturing information system: Concept, architecture and focus of future research. In Proceedings of the 2015 12th International Conference on Service Systems and Service Management (ICSSSM), Guangzhou, China, 22-24 June 2015; pp. 1-6.

60. Zhong, N.; Li, Y.; Wu, S. Effective Pattern Discovery for Text Mining. IEEE Trans. Knowl. Data Eng. 2012, 24, 30-44. [CrossRef]

61. Kostyra, D.; Reiner, J.; Natter, M.; Klapper, D. Decomposing the effects of online customer reviews on brand, price, and product attributes. Int. J. Res. Mark. 2016, 33, 11-26. [CrossRef]

62. Anh, Q.; Nagai, Y.; Le, M. Extracting Customer Reviews from Online Shopping and Its Perspective on Product Design. Vietnam J. Comput. Sci. 2019, 06, 43-56. [CrossRef]

63. Xiao, S.; Wei, C.; Dong, M. Crowd intelligence: Analyzing online product reviews for preference measurement. Inf. Manag. 2016, 53, 169-182. [CrossRef]

64. Zhao, K.; Stylianou, A.; Zheng, Y. Sources and Impacts of Social Influence from Online Anonymous User Reviews. Inf. Manag. 2017, 55, 16-30. [CrossRef]

65. Nan, H.; Ling, L.; Jie, J. Do online reviews affect product sales? The role of reviewer characteristics and temporal effects. Inf. Technol. Manag. 2008, 9, 201-214.

66. Duan, W.; Gu, B.; Whinston, A. Do online reviews matter?-An empirical investigation of panel data. Decis. Support Syst. 2008, 45, 1007-1016. [CrossRef]

67. Hou, F.; Li, B.; Chong, Y.; Yannopoulou, N.; Liu, M. Understanding and predicting what influence online product sales? A neural network approach. Prod. Plan. Control. 2017, 28, 964-975. [CrossRef]

68. Sandrin, E.; Trentin, A.; Grosso, C.; Forza, C. Enhancing the consumer-perceived benefits of a mass-customized product through its online sales configurator: An empirical examination. Ind. Manag. Data Syst. 2017, 117, 1295-1315. [CrossRef]

69. Xie, K.; So, K.; Wang, W. Joint effects of management responses and online reviews on hotel financial performance: A dataanalytics approach. Int. J. Hosp. Manag. 2017, 62, 101-110. [CrossRef]

70. Huang, L.; Dou, Z.; Hu, Y.; Huang, R. Online Sales Prediction: An Analysis with Dependency SCOR-Topic Sentiment Model. IEEE Access 2019, 7, 79791-79797. [CrossRef] 
71. Dou, Z.; Hu, Y.; Peng, C.; Huang, L.; Xiao, H. Predicting Sales Performance Based on Polarity Sentiments of Online Reviews and Manifold Dynamics Method. In Proceedings of the 2018 5th International Conference on Systems and Informatics (ICSAI), Nanjing, China, 10-12 November 2018; pp. 1138-1145.

72. Chen, G.; Yan, W.; Xu, X. An analysis of the sales and consumer preferences of e-cigarettes based on text mining of online reviews. In Proceedings of the 2016 3rd International Conference on Systems and Informatics (ICSAI), Shanghai, China, 19-21 November 2016; pp. 1045-1049.

73. Archak, N.; Ghose, A.; Ipeirotis, P. Deriving the Pricing Power of Product Features by Mining Consumer Reviews. Soc. Sci. Electron. Publ. 2011, 57, 1485-1509. [CrossRef]

74. Chong, A.; Li, B.; Ngai, E.; Chang, E.; Lee, F. Predicting online product sales via online reviews, sentiments, and promotion strategies. Int. J. Oper. Prod. Manag. 2016, 36, 358-383. [CrossRef]

75. Hu, N.; Koh, N.; Reddy, S. Ratings lead you to the product, reviews help you clinch it? The mediating role of online review sentiments on product sales. Decis. Support Syst. 2014, 57, 42-53. [CrossRef]

76. Yin, D.; Bond, S.; Han, Z. Anxious or Angry? Effects of Discrete Emotions on the Perceived Helpfulness of Online Reviews. Mis. Quarterly 2013, 38, 539-560. [CrossRef]

77. Banerjee, S.; Bhattacharyya, S.; Bose, I. Whose online reviews to trust? Understanding reviewer trustworthiness and its impact on business. Decis. Support Syst. 2017, 96, 17-26. [CrossRef]

78. Lee, J.; Sun, H.; Park, J. The role of entropy of review text sentiments on online WOM and movie box office sales. Electron. Commer. Res. Appl. 2017, 22, 42-52. [CrossRef]

79. David, S.; Pinch, T. Six degrees of reputation: The use and abuse of online review and recommendation systems. Soc. Sci. Electron. Publ. 2006, 11. [CrossRef]

80. Scholz, M.; Dorner, V.; Schryen, G.; Benlian, A. A configuration-based recommender system for supporting e-commerce decisions. Eur. J. Oper. Res. 2017, 259, 205-215. [CrossRef]

81. Kermany, N.; Alizadeh, S. A hybrid multi-criteria recommender system using ontology and neuro-fuzzy techniques. Electron. Commer. Res. 2017, 21, 50-64. [CrossRef]

82. Bendle, T.; Wang, X. Uncovering the message from the mess of big data. Bus. Horiz. 2016, 59, 115-124. [CrossRef]

83. Cui, A.; Wu, F. Utilizing customer knowledge in innovation: Antecedents and impact of customer involvement on new product performance. J. Acad. Mark. Sci. 2016, 44, 516-538. [CrossRef]

84. Bhargava, M.; Hipple, E. The Sources of Innovation. Psychopharmacol. Bull. 2007, 31, 50-58. [CrossRef]

85. Rautela, S.; Sharma, S.; Virani, S. Influence of customer participation in new product development: The moderating role of social media. Int. J. Product. Perform. Manag. 2020. ahead-of-print. [CrossRef]

86. Nishikawa, H.; Schreier, M.; Ogawa, S. User-generated versus designer-generated products: A performance assessment at Muji. Int. J. Res. Marketing. 2013, 30, 160-167. [CrossRef]

87. Ogawa, S.; Piller, F. Reducing the Risks ofNew Product Development. MIT Sloan Manag. Rev. 2006, 47, 65-71.

88. Vargo, S.; Lusch, R. Service-dominant logic: Continuing the evolution. J. Acad. Mark. Sci. 2008, 36, 1-10. [CrossRef]

89. Dahl, D.; Fuchs, C.; Schreier, M. Why and When Consumers Prefer Products of User-Driven Firms: A Social Identification Account. Manag. Sci. 2015, 61, 1978-1988. [CrossRef]

90. Erevelles, S.; Fukawa, N.; Swayne, L. Big Data consumer analytics and the transformation of marketing. J. Bus. Res. 2016, 69, 897-904. [CrossRef]

91. Tietz, R.; Morrison, P.D.; Luthje, C.; Herstatt, C. The process of user-innovation: A case study in a consumer goods setting. Int. J. Prod. Dev. 2005, 2, 321. [CrossRef]

92. Paulheim, H.; Cimiano, P. Knowledge graph refinement: A survey of approaches and evaluation methods. Semant. Web. 2017, 8, 489-508. [CrossRef]

93. Rassenfosse, G.; Bruno, V. A Policy Insight into the R\&D-Patent Relationship. Res. Policy 2009, 38, 779-792.

94. Huang, W.; Lai, C.; Chen, P. International R\&D Funding and Patent Collateral in an R\&D-Growth Model. Int. Rev. Econ. Financ. 2016, 51, 545-561.

95. Ernst, H.; Leptien, C.; Vitt, J. Inventors are not alike: The distribution of patenting output among industrial R\&D personnel. IEEE Trans. Eng. Manag. 2000, 47, 184-199.

96. Li, W.; Xie, G. Industry Strategic Management of Intellectual Property. Int. J. Bus. Manag. 2009, 2.

97. Varadarajan, R.; Yadav, M.; Shankar, V. First-Mover Advantage in the Internet-Enabled Market Environment. In Handbook of Strategic e-Business Management; Springer: Amsterdam, The Netherlands, 2014; pp. 157-185.

98. Conley, J.; Bican, P.; Ernst, H. Value Articulation: A Framework for the Strategic Management of Intellectual Property. Calif. Manag. Rev. 2013, 55, 102-120. [CrossRef]

99. Ceccagnoli, M.; Rothaermel, F. Appropriability Strategies to Capture Value from Innovation. Technol. Innov. Gener. Econ. Results 2016, 26, 3-31.

100. Cohen, W.; Goto, A.; Nagata, A.; Nelson, R.; Walsh, J. R\&D spillovers, patents and the incentives to innovate in Japan and the United States. Res. Policy 2002, 31, 1349-1367.

101. Acs, Z.; Anselin, L.; Varga, A. Patents and innovation counts as measures of regional production of new knowledge. Res. Policy 2002, 31, 1069-1085. [CrossRef]

102. Ginarte, J.; Park, W. Determinants of patent rights: A cross-national study. Res. Policy 1997, 26, 283-301. [CrossRef] 
103. Li, W. Can intellectual property rights protection and governmental R\&D investment promote Chinese enterprises' R\&D investment? Knowl. Manag. Res. Pract. 2017, 15, 551-559.

104. Penin, J. Patents versus ex post rewards: A new look. Res. Policy 2005, 34, 641-656. [CrossRef]

105. Ernst, H. Patent information for strategic technology management. World Pat. Inf. 2003, 25, 233-242. [CrossRef]

106. Dou, Z.; Wu, B.; Sun, Y.; Wang, T. The Competitiveness of Manufacturing and Its Driving Factors: A Case Study of G20 Participating Countries. Sustainability 2021, 13, 1143. [CrossRef]

107. Griliches, Z. Patent Statistics as Economic Indicators: A Survey. In RED and Productivity: The Econometric Evidence; NBER: Cambridge, MA, USA, 1998; pp. 287-343.

108. Manu, F.; Sriram, V. Innovation, marketing strategy, environment, and performance. J. Bus. Res. 2004, 35, 79-91. [CrossRef]

109. Yong, C.; Li, Z. Analysis of patent management effects on technological innovation performance. Balt. J. Manag. 2013, 8, 286-305.

110. Lopez-Vega, H.; Tell, F.; Vanhaverbeke, W. Where and how to search? Search paths in open innovation. Res. Policy 2016, 45, 125-136. [CrossRef]

111. Yayavaram, S.; Chen, W. Changes in firm knowledge couplings and firm innovation performance: The moderating role of technological complexity. Strateg. Manag. J. 2015, 36, 377-396. [CrossRef]

112. Hao, X.; Zhang, G.; Ma, S. Deep Learning. Int. J. Semant. Comput. 2016, 10, 417-439. [CrossRef]

113. Ding, Y.; Ma, L.; Ma, J.; Suo, M.; Tao, L.; Cheng, Y.; Lu, C. Intelligent fault diagnosis for rotating machinery using deep Q-network based health state classification: A deep reinforcement learning approach. Adv. Eng. Inform. 2019, 42, 100977. [CrossRef]

114. Wu, Z.; Jiang, H.; Zhao, K.; Li, X. An adaptive deep transfer learning method for bearing fault diagnosis. Measurement 2019, 151, 107227. [CrossRef]

115. Wang, Y.; Pan, Z.; Yuan, X.; Yang, C.; Gui, W. A novel deep learning based fault diagnosis approach for chemical process with extended deep belief network. ISA Trans. 2020, 96, 457-467. [CrossRef]

116. Liang, P.; Deng, C.; Wu, J.; Yang, Z.; Zhang, Z. Compound Fault Diagnosis of Gearboxes via Multi-label Convolutional Neural Network and Wavelet Transform. Comput. Ind. 2019, 113, 103132. [CrossRef]

117. Yang, C.; Liu, C.; Zhang, X.; Nepal, S.; Chen, J. A Time Efficient Approach for Detecting Errors in Big Sensor Data on Cloud. IEEE Trans. Parallel Distrib. Syst. 2015, 26, 329-339. [CrossRef]

118. Dean, J. MapReduce: Simplified Data Processing on Large Clusters. In Proceedings of the Symposium on Operating System Design \& Implementation, San Francisco, CA, USA, 6-8 December 2004.

119. Lindell, Y.; Riva, B. Cut-and-Choose Yao-Based Secure Computation in the Online/Offline and Batch Settings. In Proceedings of the International Cryptology Conference, Santa Barbara, CA, USA, 17-21 August 2014; Springer: Berlin/Heidelberg, Germany, 2014; pp. 476-494.

120. Kumar, A.; Shankar, R.; Chou, D.; Hary, A.; Thakur, L. A big data MapReduce framework for fault diagnosis in cloud-based manufacturing. Int. J. Prod. Res. 2016, 54, 7060-7073. [CrossRef]

121. Wan, J.; Tang, S.; Li, D.; Wang, S.; Liu, C. A Manufacturing Big Data Solution for Active Preventive Maintenance. IEEE Trans. Ind. Inform. 2017, 13, 2039-2047. [CrossRef]

122. Bekooij, M.; Wiggers, M.; Meerbergen, V.; Falk, H.; Marwedel, P. Efficient Buffer Capacity and Scheduler Setting Computation for Soft Real-Time Stream Processing Applications. In Proceedings of the 10th International Workshop on Software \& Compilers for Embedded Systems, Nice, France, 20 April 2007; pp. 1-10.

123. Huo, Z.; Mukherjee, M.; Shu, L.; Chen, Y.; Zhou, Z. Cloud-based Data-intensive Framework towards fault diagnosis in large-scale petrochemical plants. In Proceedings of the 2016 International Wireless Communications and Mobile Computing Conference (IWCMC), Paphos, Cyprus, 5-9 September 2016; pp. 1080-1085.

124. Xu, Y.; Sun, Y.; Wan, J.; Liu, X.; Song, Z. Industrial Big Data for Fault Diagnosis: Taxonomy, Review, and Applications. IEEE Access 2017, 13, 2039-2047. [CrossRef]

125. Hinton, G.; Salakhutdinov, R. Reducing the Dimensionality of Data with Neural Networks. Science 2016, 313, 504-507. [CrossRef]

126. Qi, Y.; Wei, Y.; Shen, C.; Jiang, X.; Zhu, Z. Hierarchical diagnosis network based on sparse deep neural networks and its application in bearing fault diagnosis. In Proceedings of the 2017 Prognostics and System Health Management Conference (PHM-Harbin), Harbin, China, 9-12 July 2017; pp. 1-7.

127. Tamilselvan, P.; Wang, P. Failure diagnosis using deep belief learning based health state classification. Reliab. Eng. Syst. Safety 2013, 115, 124-135. [CrossRef]

128. Feng, J.; Lei, Y.; Jing, L.; Xin, Z.; Na, L. Deep neural networks: A promising tool for fault characteristic mining and intelligent diagnosis of rotating machinery with massive data. Mech. Syst. Signal Process. 2016, 72-73, 303-315.

129. Ma, S.; Zhang, Y.; Liu, Y.; Yang, H.; Ren, S. Data-driven sustainable intelligent manufacturing based on demand response for energy-intensive industries. J. Clean. Prod. 2020, 274, 123155. [CrossRef]

130. Lade, P.; Ghosh, R.; Srinivasan, S. Manufacturing Analytics and Industrial Internet of Things. IEEE Intell. Syst. 2017, 32, 74-79. [CrossRef]

131. Basanta-Val, P. An Efficient Industrial Big-Data Engine. IEEE Trans. Ind. Inform. 2017, 14, 1361-1369. [CrossRef]

132. Wang, F.; Li, G.; Li, S.; Zhu, Y.; Wang, Y. A Continuous Data Acquisition System Based on CompactPCI for EAST Tokamak. IEEE Trans. Nucl. Sci. 2010, 57, 669-672. [CrossRef]

133. Pavlovic, I.; Miklavcic, D. Web-Based Electronic Data Collection System to Support Electrochemotherapy Clinical Trial. IEEE Trans. Inf. Technol. Biomed. 2007, 11, 222-230. [CrossRef] 
134. Bender, A.; Ward, J.; Worrall, S.; Moreyra, M.; Konrad, S.; Masson, F.; Nebot, E. A Flexible System Architecture for Acquisition and Storage of Naturalistic Driving Data. IEEE Trans. Intell. Transp. Syst. 2016, 17, 1748-1761. [CrossRef]

135. Wang, T.; Ke, H.; Zheng, X.; Wang, K.; Liu, A. Big Data Cleaning Based on Mobile Edge Computing in Industrial Sensor-Cloud. IEEE Trans. Ind. Inf. 2019, 16, 1321-1329. [CrossRef]

136. Wang, Y.; Wei, W.; Deng, Q.; Liu, W.; Song, H. An Energy-Efficient Skyline Query for Massively Multidimensional Sensing Data. Sensors 2016, 16, 83. [CrossRef] [PubMed]

137. Li, X.; Li, D.; Wan, J.; Vasilakos, A.; Lai, C.; Wang, S. A review of industrial wireless networks in the context of Industry 4.0. Wirel. Netw. 2017, 23, 23-41. [CrossRef]

138. Wang, H.; Tan, S.; Zhu, Y.; Li, M. Deterministic Scheduling with Optimization of Average Transmission Delays in Industrial Wireless Sensor Networks. IEEE Access 2020, 8, 18852-18862. [CrossRef]

139. Jin, X.; Kong, F.; Kong, L.; Wang, H.; Xia, C. A Hierarchical Data Transmission Framework for Industrial Wireless Sensor and Actuator Networks. IEEE Trans. Ind. Inf. 2017, 13, 2019-2029. [CrossRef]

140. Dong, G.; Yan, C.; Wei, C.; Guo, D. Integrated system of industrial data acquisition and monitor with CDMA 1x technology. In Proceedings of the 2008 2nd International Conference on Anti-counterfeiting, Security and Identification, Guiyang, China, 20-23 August 2008; pp. 424-427.

141. Yao, Y.; Wang, Y.; Liu, X.; Cheng, H.; Liu, M.; Xu, D. Analysis, Design, and Implementation of a Wireless Power and Data Transmission System Using Capacitive Coupling and Double-Sided LCC Compensation Topology. IEEE Trans. Ind. Appl. 2018, 55, 541-551. [CrossRef]

142. Cho, K.; Yun, H.; Kim, N. Robust Data Hiding for MCLT Based Acoustic Data Transmission. IEEE Signal Process. Lett. 2010, 17, 679-682. [CrossRef]

143. Singh, A.; Garg, S.; Kaur, K.; Batra, S.; Kumar, N.; Choo, K. Fuzzy-Folded Bloom Filter-as-a-Service for Big Data Storage in the Cloud. IEEE Trans. Ind. Inf. 2019, 15, 2338-2348. [CrossRef]

144. Bo, M.; Hong, J.; Wu, S.; Lei, T. Leveraging Data Deduplication to Improve the Performance of Primary Storage Systems in the Cloud. IEEE Trans. Comput. 2016, 65, 1775-1788.

145. Xia, Q.; Xu, Z.; Liang, W.; Yu, S.; Guo, S.; Zomaya, A. Efficient Data Placement and Replication for QoS-Aware Approximate Query Evaluation of Big Data Analytics. IEEE Trans. Parallel Distrib. Syst. 2019, 30, 2677-2691. [CrossRef]

146. Benghanem, M.; Maafi, A. Data acquisition system for photovoltaic systems performance monitoring. IEEE Trans. Instrum. Meas. 1998, 47, 30-33. [CrossRef]

147. Yoon, S.; Kim, I.; Lee, K. The Architectural Design of Storage System for Power Data Management. In Proceedings of the 2018 IEEE International Conference on Big Data and Smart Computing (BigComp), Bangkok, Thailand, 17-20 January 2018 ; pp. 736-738.

148. Tomar, D.; Agarwal, S. A survey on Data Mining approaches for healthcare. Int. J. Bio-Sci. Bio-Technol. 2013, 5, 241-266. [CrossRef]

149. Ali, M.; Ali, R.; Khan, W.; Han, S.; Bang, J.; Hur, T.; Kim, D.; Lee, S.; Kang, B. A Data-Driven Knowledge Acquisition System: An End-to-End Knowledge Engineering Process for Generating Production Rules. IEEE Access 2018, 6, 15587-15607. [CrossRef]

150. Shu, W.; Qian, W.; Xie, Y. Knowledge Acquisition Approach based on Incremental Objects from Data with Missing Values. IEEE Access 2019, 7, 54863-54878. [CrossRef]

151. Yeung, D.; Tsang, E. Fuzzy knowledge representation and reasoning using Petri nets. Expert Syst. Appl. 1994, 7, 281-289. [CrossRef]

152. Tang, Y.; Hong, M. Modified Fractal Signature (MFS): A New Approach to Document Analysis for Automatic Knowledge Acquisition. IEEE Trans. Knowl. Data Eng. 1997, 9, 747-762. [CrossRef]

153. Gaines, B.; Shaw, M. Eliciting Knowledge and Transferring It Effectively to a Knowledge-Based System. IEEE Trans. Knowl. Data Eng. 2002, 5, 4-14. [CrossRef]

154. Liu, H.; Liu, L.; Lin, Q.; Liu, N. Knowledge Acquisition and Representation Using Fuzzy Evidential Reasoning and Dynamic Adaptive Fuzzy Petri Nets. IEEE Trans. Cybern. 2013, 43, 1059-1072. [CrossRef]

155. $\mathrm{Hu}, \mathrm{W}$. Framework of Knowledge Acquisition and Sharing in Multiple Projects for Contractors. In Proceedings of the 2008 International Symposium on Knowledge Acquisition and Modeling, Wuhan, China, 21-22 December 2008; pp. $172-176$.

156. Chen, S.; Ke, J.; Chang, J. Knowledge representation using fuzzy Petri nets. IEEE Trans. Knowl. Data Eng. 1990, 2, 311-319. [CrossRef]

157. Looney, C. Fuzzy Petri nets for rule-based decision making. IEEE Trans. Syst. Man Cybern. 1988, 18, 178-183. [CrossRef]

158. Liu, H.; Lin, Q.; Mao, L.; Zhang, Z. Dynamic Adaptive Fuzzy Petri Nets for Knowledge Representation and Reasoning. IEEE Trans. Syst. Man Cybern. Syst. 2013, 43, 1399-1410. [CrossRef]

159. Jong, W.; Shiau, Y.; Horng, Y.; Chen, H.; Chen, S. Temporal knowledge representation and reasoning techniques using time Petri nets. IEEE Trans. Syst. Man Cybern. Part B 1999, 29, 541-545. [CrossRef] [PubMed]

160. Kargin, A.; Petrenko, T. Knowledge Representation in Smart Rules Engine. In Proceedings of the 2019 3rd International Conference on Advanced Information and Communications Technologies (AICT), Lviv, Ukraine, 2-6 July 2019; pp. 231-236.

161. Ebrahimipour, V.; Yacout, S. Ontology-Based Schema to Support Maintenance Knowledge Representation with a Case Study of a Pneumatic Valve. IEEE Trans. Syst. Man Cybern. Syst. 2015, 45, 702-712. [CrossRef]

162. Li, P.; Chen, Z.; Yang, L.; Gao, J.; Zhang, Q.; Deen, M. An Incremental Deep Convolutional Computation Model for Feature Learning on Industrial Big Data. IEEE Trans. Ind. Inf. 2019, 15, 1341-1349. [CrossRef] 
163. Deng, X.; Wang, X. Incremental learning of dynamic fuzzy neural networks for accurate system modeling. Fuzzy Sets Syst. 2009, 160, 972-987. [CrossRef]

164. Filev, D.; Chinnam, R.; Tseng, F.; Baruah, P. An Industrial Strength Novelty Detection Framework for Autonomous Equipment Monitoring and Diagnostics. IEEE Trans. Ind. Inf. 2010, 6, 767-779. [CrossRef]

165. Jo, K.; Kim, J.; Kim, D.; Jang, C.; Sunwoo, M. Development of Autonomous Car-Part I: Distributed System Architecture and Development Process. IEEE Trans. Ind. Electron. 2014, 61, 7131-7140. [CrossRef]

166. Tripkovic, S.; Delic, M. Knowledge databases in control systems. In Proceedings of the IECON'99, 25th Annual Conference of the IEEE Industrial Electronics Society, San Jose, CA, USA, 29 November-3 December 1999; pp. 642-645.

167. Doroodgar, B.; Liu, Y.; Nejat, G. A Learning-Based Semi-Autonomous Controller for Robotic Exploration of Unknown Disaster Scenes While Searching for Victims. IEEE Trans. Cybern. 2017, 44, 2719-2732. [CrossRef]

168. Rahman, M.; Sanchez-Tamayo, N.; Gonzalez, G.; Agarwal, M.; Wachs, J. Transferring Dexterous Surgical Skill Knowledge between Robots for Semi-autonomous Teleoperation. In Proceedings of the 2019 28th IEEE International Conference on Robot and Human Interactive Communication (RO-MAN), New Delhi, India, 14-18 October 2019; pp. 1-6.

169. Qasim, I.; Anwar, M.; Azam, F.; Tufail, H.; Zafar, M. A Model-driven Mobile HMI Framework (MMHF) for Industrial Control Systems. IEEE Access 2020, 8, 10827-10846. [CrossRef]

170. Joo, T.; Shin, D. Formalizing Human-Machine Interactions for Adaptive Automation in Smart Manufacturing. IEEE Trans. Hum. -Mach. Syst. 2019, 49, 529-539. [CrossRef]

171. Meschtscherjakov, A.; Tscheligi, M.; Szostak, D.; Krome, S.; Pfleging, B.; Ratan, R.; Politis, I.; Baltodano, S.; Miller, D.; Ju, W. $\mathrm{HCI}$ and Autonomous Vehicles: Contextual Experience Informs Design. In Proceedings of the 2016 CHI Conference Extended Abstracts on Human Factors in Computing Systems, San Jose, CA, USA, 7-12 May 2016; pp. 3542-3549.

172. Xia, L.; Zhu, J.; Zhe, Y. Kcansee engineering applied in Human-Computer Interaction Design. In Proceedings of the 2009 IEEE 10 th International Conference on Computer-Aided Industrial Design \& Conceptual Design, Wenzhou, China, 26-29 November 2009; pp. 1287-1290.

173. Erol, B.; Majumdar, A.; Benavidez, P.; Rad, P.; Choo, K.; Jamshidi, M. Toward Artificial Emotional Intelligence for Cooperative Social Human-Machine Interaction. IEEE Trans. Comput. Soc. Syst. 2020, 7, 234-246. [CrossRef]

174. Filho, R.; Huang, C.; Yu, B.; Venkataramana, R.; El-Messidi, A.; Sharber, D.; Westerheide, J.; Alkadi, N. Semi-Autonomous Industrial Robotic Inspection: Remote Methane Detection in Oilfield. In Proceedings of the 2018 IEEE International Conference on Edge Computing (EDGE), San Francisco, CA, USA, 2-7 July 2018; pp. 17-24.

175. Mostafa, S.; Mustapha, A.; Shamsudin, A.; Ahmad, A.; Gunasekaran, S. A Real-Time Autonomous Flight Navigation Trajectory Assessment for Unmanned Aerial Vehicles. In Proceedings of the 2018 International Symposium on Agent, Multi-Agent Systems and Robotics (ISAMSR), Putrajaya, Malaysia, 27 August 2018; pp. 1-6.

176. Doering, M.; Glas, D.; Ishiguro, H. Modeling Interaction Structure for Robot Imitation Learning of Human Social Behavior. IEEE Trans. Hum. Mach. Syst. 2019, 49, 219-231. [CrossRef]

177. Liu, X.; Zhang, L. Design and Implementation of Human-Computer Interaction Adjustment in Nuclear Power Monitoring System. Microprocess Microsyst. 2021, 104096. [CrossRef]

178. Liang, Z.; Jian, Z.; Zheng, L.; Nan, L. The Application of Human-Computer Interaction Idea in Computer Aided Industrial Design. In Proceedings of the 2017 International Conference on Computer Network, Electronic and Automation (ICCNEA), Xi'an, China, 23-25 September 2017; pp. 160-164.

179. Feng, L.; Yin, Q.; Wang, L.; Xue, Q. Human-computer interaction analysis of turret based on context-aware. In Proceedings of the 2012 IEEE International Conference on Industrial Engineering and Engineering Management, Hong Kong, China, 10-13 December 2012; pp. 1253-1256.

180. Quintas, J.; Menezes, P.; Dias, J. Information Model and Architecture Specification for Context Awareness Interaction Decision Support in Cyber-Physical Human-Machine Systems. IEEE Trans. Hum. Mach. Syst. 2016, 47, 323-331. [CrossRef]

181. Herrera, D.; Roberti, F; Toibero, M.; Carelli, R. Human-Robot Interaction: Legible behavior rules in passing and crossing events. IEEE Lat. Am. Trans. 2016, 14, 2644-2650. [CrossRef]

182. Xu, Z.; Wang, R.; Yue, X.; Liu, T.; Chen, C.; Fang, S. FaceME: Face-to-Machine Proximity Estimation Based on RSSI Difference for Mobile Industrial Human Machine Interaction. IEEE Trans. Ind. Inform. 2018, 14, 3547-3558. [CrossRef]

183. Bowyer, S.; Rodriguez y Baena, F. Dissipative Control for Physical Human-Robot Interaction. IEEE Trans. Robot. 2015, 31, 1281-1293. [CrossRef]

184. Albuainain, H.; Almelihi, S.; Alkhaidi, S.; Alzahrani, R.; Alqahtani, A. Human Computer Interaction Study on Fujifilm Instax Mini 8 Camera Using Evaluation Techniques. In Proceedings of the 2019 2nd International Conference on Computer Applications \& Information Security (ICCAIS), Riyadh, Saudi Arabia, 1-3 May 2019; pp. 1-6.

185. Milanovic, N.; Malek, M. Service-Oriented Operating System: A Key Element in Improving Service Availability. In Service Availability, 4th International Service Availability Symposium, ISAS 2007, Lecture Notes in Computer Science; Springer: Amsterdam, The Netherlands, 2007; p. 4526.

186. Stadje, W. Availability of an operating system during a given time interval: A dynamic programming approach. Nav. Res. Log. 1996, 43, 589-602. [CrossRef]

187. Broek, E. Quantifying the user experience: Practical statistics for user research. Comput. Rev. 2013. 
188. Hu, M.; Peng, B.; Zhang, N. The research of human-machine interactions unity on IOS and android smartphone platform. In Proceedings of the 2014 9th International Conference on Computer Science \& Education, Vancouver, Canada, 22-24 August 2014; pp. 640-643.

189. Meng, L.; Wei, J.; Xi, Z.; Bolton, M. A Formal Machine-Learning Approach to Generating Human-Machine Interfaces from Task Models. IEEE Trans. Hum. Mach. Syst. 2017, 47, 822-833.

190. Zeng, Q.; Duan, Q.; Jiang, B. Integrated Evaluation of Hardware and Software Interfaces for Automotive Human-Machine Interaction. IET Cyber-Phys. Syst. Theory Appl. 2019, 4. [CrossRef]

191. Benbya, H.; Mckelvey, B. Using Coevolutionary and Complexity Theories to Improve IS Alignment: A Multi-Level Approach. J. Inf. Technol. 2006, 21, 284-298. [CrossRef]

192. Merali, Y.; Papadopoulos, T.; Nadkarni, T. Information systems strategy: Past, present, future? J. Strateg. Inf. Syst. 2012, 21, 125-153. [CrossRef]

193. Weichhart, G.; Molina, A.; Chen, D.; Whitman, L.; Vernadat, F. Challenges and current developments for Sensing, Smart and Sustainable Enterprise Systems. Comput. Ind. 2016, 79, 34-46. [CrossRef]

194. Pintus, A.; Carboni, D.; Piras, A. Paraimpu: A platform for a social web of things. In Proceedings of the 21st International Conference on World Wide Web, Lyon, France, 16-20 April 2012; pp. 401-404.

195. Chung, T.; Mashal, I.; Alsaryrah, O.; Chang, C.; Hsu, T.; Li, P.; Kuo, W. MUL-SWoT: A Social Web of Things Platform for Internet of Things Application Development. In Proceedings of the 2014 IEEE International Conference on Internet of Things (iThings), and IEEE Green Computing and Communications (GreenCom) and IEEE Cyber, Physical and Social Computing (CPSCom), Taipei, Taiwan, 1-3 September 2014; pp. 296-299.

196. Azad, M.; Bag, S.; Hao, F.; Shalaginov, A. Decentralized Self-Enforcing Trust Management System for Social Internet of Things. IEEE Internet Things J. 2020, 7, 2690-2703. [CrossRef] 